University of Louisville

ThinkIR: The University of Louisville's Institutional Repository

Electronic Theses and Dissertations

$12-2002$

\title{
Six sigma : changing a culture.
}

Lee E. Leathers 1966-

University of Louisville

Follow this and additional works at: https://ir.library.louisville.edu/etd

\section{Recommended Citation}

Leathers, Lee E. 1966-, "Six sigma : changing a culture." (2002). Electronic Theses and Dissertations.

Paper 802.

https://doi.org/10.18297/etd/802

This Master's Thesis is brought to you for free and open access by ThinkIR: The University of Louisville's Institutional Repository. It has been accepted for inclusion in Electronic Theses and Dissertations by an authorized administrator of ThinkIR: The University of Louisville's Institutional Repository. This title appears here courtesy of the author, who has retained all other copyrights. For more information, please contact thinkir@louisville.edu. 
SIX SIGMA: CHANGING A CULTURE

\author{
By \\ Lee E. Leathers \\ BS Industrial Technology, 1989 \\ Eastern Illinois University
}

\begin{abstract}
A Thesis
Submitted to the Faculty of the

Graduate School of the University of Louisville in Partial Fulfillment of the Requirements for the Degree of

Master of Science

Department of Industrial Engineering University of Louisville

Louisville, Kentucky
\end{abstract}

December 2002 

SIX SIGMA: CHANGING A CULTURE

$$
\text { By }
$$

Lee E. Leathers

BS Industrial Technology, 1989

Eastern Illinois University

\section{A Thesis Approved on}

July 17, 2002

by the following Thesis Committee:

Dr. William E. Biles, Thesis Director

Dr. John S. Usher

Dr. Julius P. Wong 


\section{ACKNOWLEDGMENTS}

I would like to thank all of the professors at the University of Louisville with whom I have worked. Specifically, I would like to than Dr. Biles who gave me the guidance, confidence and reassurance that I needed to complete the MSIE program.

General Electric gave me the opportunity to apply my education to real business applications. I would like to thank the Black Belts, managers, and engineers with whom I have worked while at General Electric Company. Thanks for the countless hours of discussions we had on Six Sigma tools and methods. Most of all, thanks for the translation of your knowledge. These people who have worked the closest with me on a daily basis, and who have done the most to help me learn and understand Six Sigma Ron Surmick, Ron Wilson, Don Hatfield, Matt Elam, Jeff Schnitzer, John Sciaroni, Claude Yee, Cesar Vasquez, Terry Royer, Dave Laube, Mike Randolph, Kerry Minor, Jose Olivencia and Lars Engman.

I would like to thank my parents, Ron and Sue, for their constant support. I would like to thank my sister, Ronda, who is currently a college professor herself, for the advice and editing help.

Most of all I would like to thank my wife, Jackie, who never gets enough recognition from me for being such an outstanding wife, mother, and support foundation regardless of the endeavor. 


\section{ABSTRACT \\ Six Sigma: Changing a Culture \\ Lee E. Leathers}

December 17, 2002

The objective of this thesis was to apply what was learned from Six Sigma while working for General Electric, towards real applications to improve processes. Two manufacturing problems were targeted. One of the issues dealt with variation, in an assembly process, which caused a large amount of missed opportunities. The other issue was based on defects caused by a reflector coating process that was creating haze and affecting lumens generated by the lamp.

While analyzing the missed opportunity issue, a DMAIC approach was followed, measuring the collected data and analyzing the variation and mean of the processes by the use of box plots, Cause and Effect analysis, Pareto Diagrams, and Statistical analysis. After analyzing the data, three improvements on the machine were implemented. After analyzing the haze issue, a DOE was conducted to prove what factor was causing the haze.

The missed opportunities were improved upon by implementing a preventative maintenance schedule and driving some "Quick Hit" projects for a total annualized savings of $\$ 140,000$. The haze issue was proven, by a very simple $2 \mathrm{X} 2$ Design of Experiment, to be caused by the environment. By controlling the environmental conditions, the business was able to save $\$ 121,000$ annualized. 
TABLE OF CONTENTS

PAGE

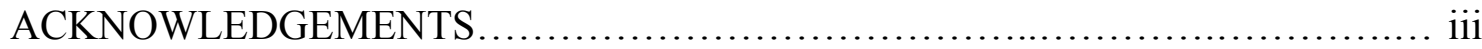

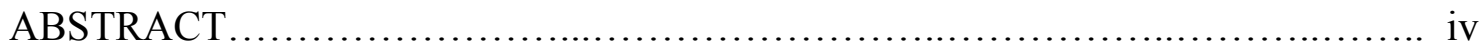

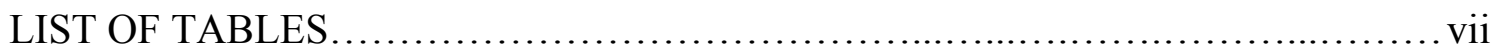

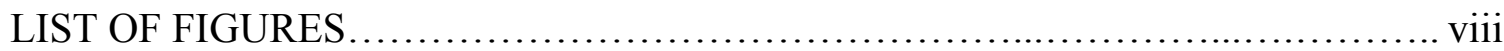

CHAPTER

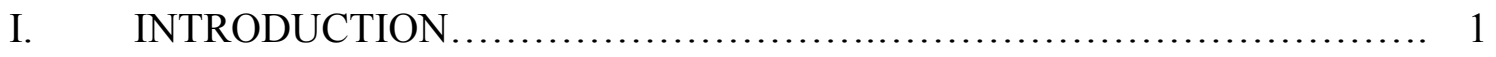

Background of the Problem............................................. 1

Statement of the Problem................................................. 2

Research Objectives........................................... 2

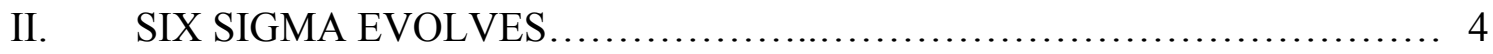

What is "Six Sigma"................................................ 4

Motorola.......................................................... 12

Honeywell/Allied Signal.............................................. 13

General Electric................................................... 14

Other Programs........................................................ 15

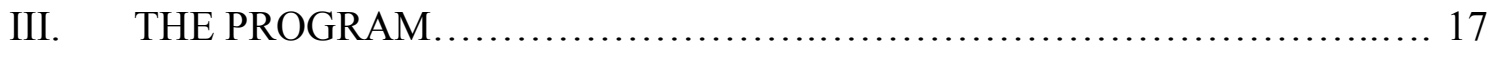

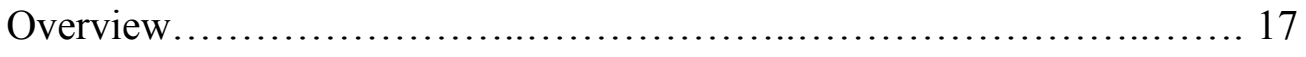

Infrastructure ........................................................ 19

Project Identification, Organization, and Execution.......................22 


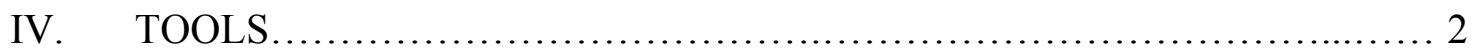

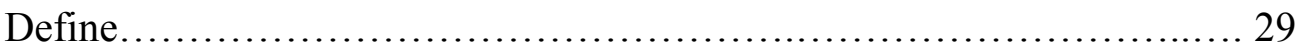

Measure..................................................... 31

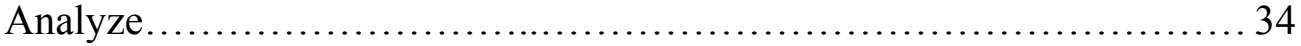

Improve.......................................................... 39

Control........................................................... 41

V. CASE STUDIES .............................................. 44

Case Study I - Preventative Maintenance............................. 44

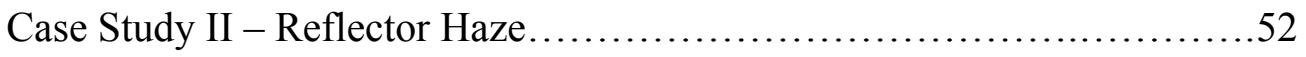

VI. SUMMARY AND CONCLUSIONS ................................... 59

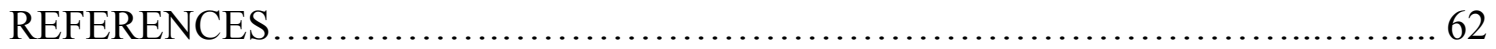

CURRICULUM VITAE .................................................. 64 


\section{LIST OF TABLES}

TABLE

PAGE

1. Defective Parts per Million Opportunities............................... 9

2. Initial Savings..................................................... 16

3. Define the Problem...................................................... 24

4. Sample Data Collection Sheet.......................................... 25

5. Design of Experiment............................................. 40

6. Downtime Data................................................... 46

7. Cause and Effect Matrix for Reactive Maintenance...........................50

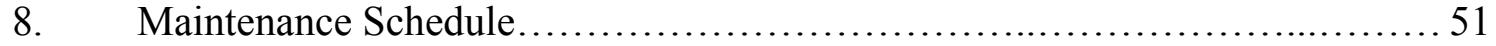

9. Baseline of Reflector Defects......................................... 52

10. Cause and Effect Matrix of Haze Defects.................................53

11. Reflector Coating Project Results....................................58

12. Annualized Savings................................................ 58 


\section{LIST OF FIGURES}

FIGURE PAGE

1. Population Standard Deviation..................................... 6

2. Sample Standard Deviation......................................... 7

3. Normal Distribution............................................ 8

4. Sigma Relationship to a Normal Distribution.......................... 8

5. Effects of a $1.5 \sigma$ shift where only $3.4 \mathrm{ppm}$ fail to meet specifications.......... 9

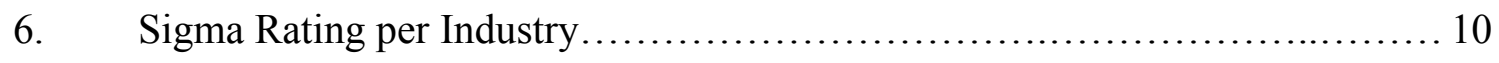

7. Process Map.................................................... 30

8. Rolled Throughput Yield Formula....................................... 30

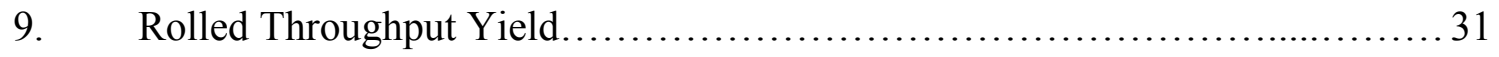

10. Gage Repeatability \& Reproducibility ............................... 31

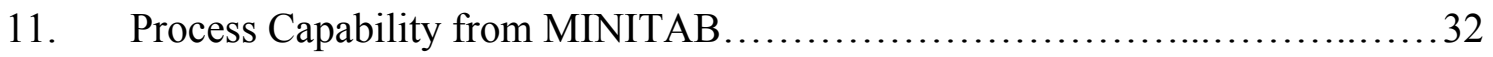

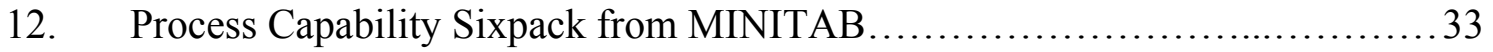

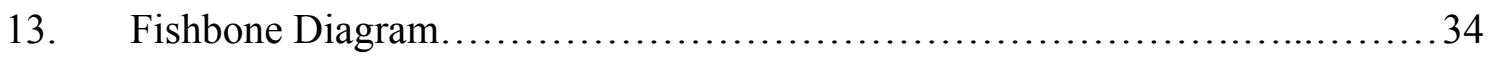

14. Cause and Effect Matrix ............................................. 35

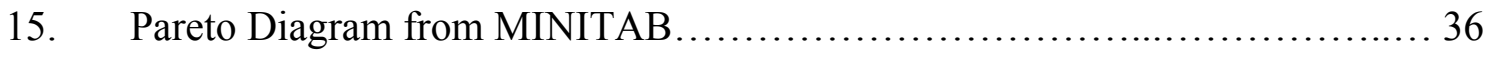

16. Failure Mode Effects Analysis..................................... 37

17. Regression Plot from MINITAB ...................................... 38

18. Design for Six Sigma........................................... 41

19. Statistical Process Control Chart....................................... 43 
20. Index Machine Process Map....................................... 44

21. Pareto of Defects....................................................... 47

22. Box Plot of Defects.............................................. 48

23. Timeline of Events.................................................... 49

24. Significant Difference After Quick Hits.................................. 50

25. Macro Process Map - Reflector Process................................ 52

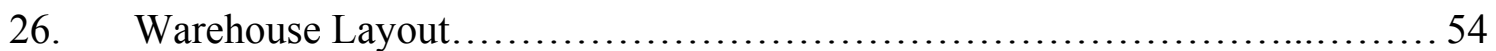

27. Micro Process Map - Reflector Coating................................. 54

28. DOE for Reflector Coating .......................................... 56

29. DOE Raw Reflector Variation Reduction..................................57

30. Reflector Coating DOE Results....................................... 57 


\section{CHAPTER I}

\section{INTRODUCTION}

\section{$\underline{\text { Background of the problem }}$}

The concept of continuous improvement is common practice in most industry today. It is even a required metric for the new ISO 9001:2000 quality standard. But what does Continuous Improvement really mean? Simply put, as time goes by processes are expected to improve. Time on the job, by itself, will make most people more efficient because they become better trained. But can one be sure that the same person will be doing the same job tomorrow? Maybe new equipment is the. Or maybe it is simply a matter of streamlining the process that is in place. Perhaps even a different type of raw material or new supplier would improve the process. These are all questions that quality and process engineers, who deal with continuous improvement issues, face every day. Some of these analysts have found the field of statistics to be quite helpful in analyzing these types of issues. However, the statistics are a means, not the end. And what about teamwork - aren't two heads better than one? What about the manager who has all of the power and control to drive change, but is afraid to because he doesn't understand what his engineer is talking about. How much better could an organization improve if everyone in the company knew basic statistics and methods of process improvement? Many businesses and industries want to improve their operations. They understand they need to improve their processes. However, many find it difficult to package these ideas in a 
logical way to communicate the discipline and rigor down through the organization and across an entire business. Six Sigma is a program that claims to provide a foundation for this type of goal.

\section{$\underline{\text { Statement of the Problem }}$}

The basics of Six Sigma are nothing new to the field of Quality Engineering. It uses standard statistical tools to analyze data taken from existing processes. It uses a very methodical approach, not unlike many problem-solving models being taught in technical universities today. What is different about the Six Sigma initiative that other quality programs fail to include? Furthermore, how can some companies claim to make such a profit on this program while others write it off as a hype or fad?

\section{$\underline{\text { Research Objectives }}$}

The objective of this thesis is to analyze what Six Sigma means, to investigate the impact Six Sigma has had on certain organizations, and to show some real-world case studies of Six Sigma methodology. Part of this thesis will be dedicated to some of the statistical and analysis tools that are use in Six Sigma Projects. The intent of this thesis is not to make an expert out of the reader. It briefly touches on some of the common tools used in Six Sigma projects and gives an overview of the philosophy of Six Sigma - what it means to different people. Six Sigma means many things. These differences will be identified and defined. This thesis will discuss some of the organizations and resources that are dedicated to educating others in the use of Six Sigma methodology. The Six Sigma drive toward quality improvement has affected many businesses. This thesis will review the bottom line - how much money has been saved by some companies through the use of Six Sigma methodology. Finally, this thesis will summarize with some 
thoughts on why some companies may have failed. This thesis assumes a basic working knowledge of statistics on the reader's part. It is by no means conclusive of Six Sigma methods, practices, or theory. 


\section{CHAPTER II}

\section{SIX SIGMA EVOLVES}

Six Sigma is all about proactive, logical thinking - backing decisions up with what we know rather than what we think. "Show me the data" is commonly heard in any facility that is motivated by a Six Sigma program. No true Six Sigma Black Belt would dare show up to present a theory without data to back up the proposed actions. And that is one of the characteristics that makes Six Sigma unique. It is not any special set of magical tools that mathematicians have developed to change industry. Six Sigma is many things, but most importantly it is a philosophy to process improvement. It is a philosophy of how things are done and controlled in an organization. Some people claim it to be a lot of hype. Some people claim it as the be-all-end-all. Actually it is neither. Six Sigma is simply a program that some business leaders, who understood both the power of Quality Engineering and business needs, developed by combining traditional statistical tools with a very structured basic problem-solving methodology. Six Sigma methods can be used to improve nearly anything, from golf games to business operating plans.

\section{What is "Six Sigma"}

Six Sigma is many things to many people. This paper will consider three ideas:

1) Six Sigma as a Metric.

2) Six Sigma as an Initiative.

3) Six Sigma as a Philosophy. 
As a Metric, Six Sigma is a method of measuring the robustness of a process. Process improvement is a goal in many activities, but how does one measure the efficiency at which they are functioning? Take, for instance, the job of laying shingles for a roofing company. A task that is very common in laying shingles on a house is that of hammering a nail through a shingle and into the roof. When a carpentry apprentice begins with a roofing company, that person moves slowly and makes many mistakes because they do not have much experience. They have not yet programmed their brain to complete this task with the speed and dexterity that will make the process efficient. However, as more time is spent at this task, that person masters the basic roofing skills by executing the task repeatedly and by learning better methods as they watch other experienced roofers who have developed quick and easy methods to reduce error in their work. After several years, this roofing apprentice has improved the process of hammering nails considerably. Now, instead of successfully nailing about 7 nails for every 10 attempts, this carpenter is successfully nailing about 94 nails for every 100 attempts. This roofer has moved the process efficiency of hammering roofing nails from a 2 sigma process to over a 3 sigma process. If this now experienced roofer eventually becomes good enough to only make about 6 mistakes for every 1000 nails attempted, then the process was improved to 4 sigma. This example shows how we can measure any process in terms of sigma efficiency. It stands to reason, then, that the lower the defect (error) rate, the more efficient the process becomes and hence more robust.

The Greek letter $\sigma$ (sigma) is used in mathematical statistics to represent the standard deviation of a distribution. In mathematical statistics, letters symbolized in Greek are used to represent parameters, and their values are always unknown. So, the value of sigma is always unknown, but it is estimated by calculating the standard deviation from a representative sample. [4, p181] 
A review of some basic statistical theory will show the relationship of Six Sigma and the example above. Population standard deviation (Figure 1) is usually a theoretical number because most items we analyze are not finite. In other words, if one is dealing with a population that is finite, there is probably no reason to analyze it because it is no longer functioning. In practical statistical analysis, we use samples of a population to generate sample standard deviations. Standard deviation is simply a method of measuring the variation within a process, around the mean. In Figure 1, the formula under the square root sign is variance. Standard deviation is the square root of variation.

In Figure $1 \mathrm{x}_{\mathrm{i}}=$ sample mean, $\mu=$ theoretical mean, and $\mathrm{N}=$ population size. The equivalent formula for a process that is not finite is shown in Figure 2.

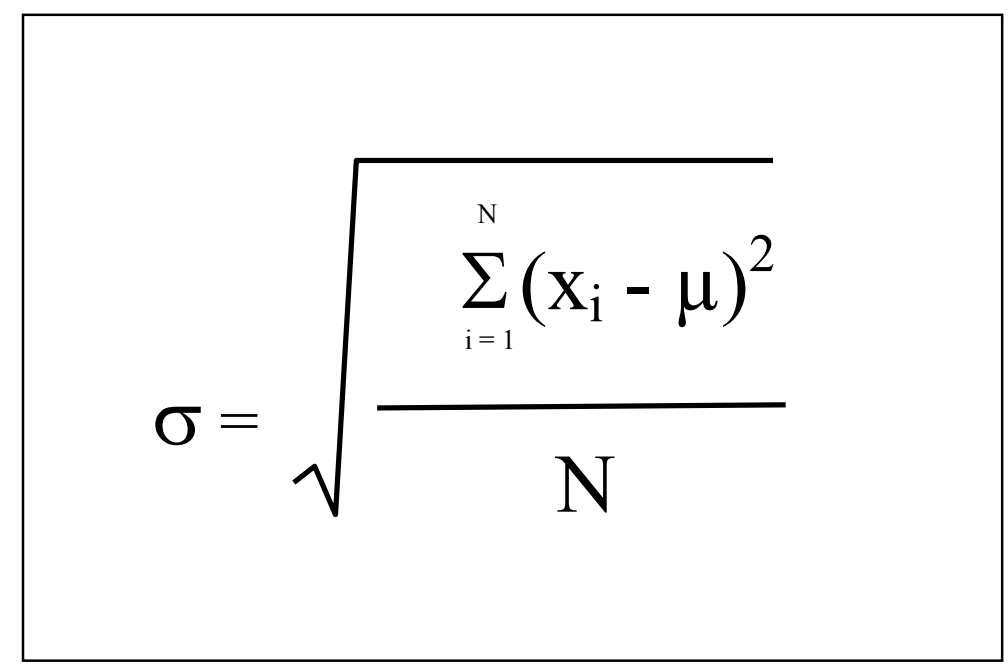

Figure 1. Population Standard Deviation 


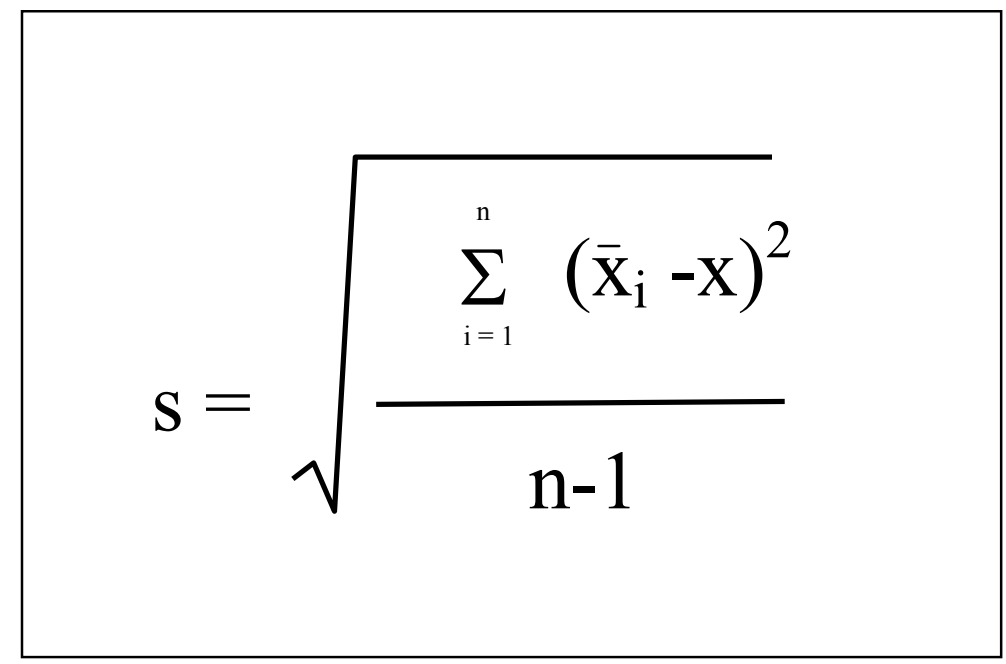

Figure 2. Sample Standard Deviation

One key goal in process improvement is to minimize variation, so you can predict outcomes of events. This is the relationship of standard deviation to process improvement - variation metrics.

So what does this mean? Figure 3 shows a normal distribution of a process and how a defect is associated with the curve. Figure 4 shows that as the sigma number 


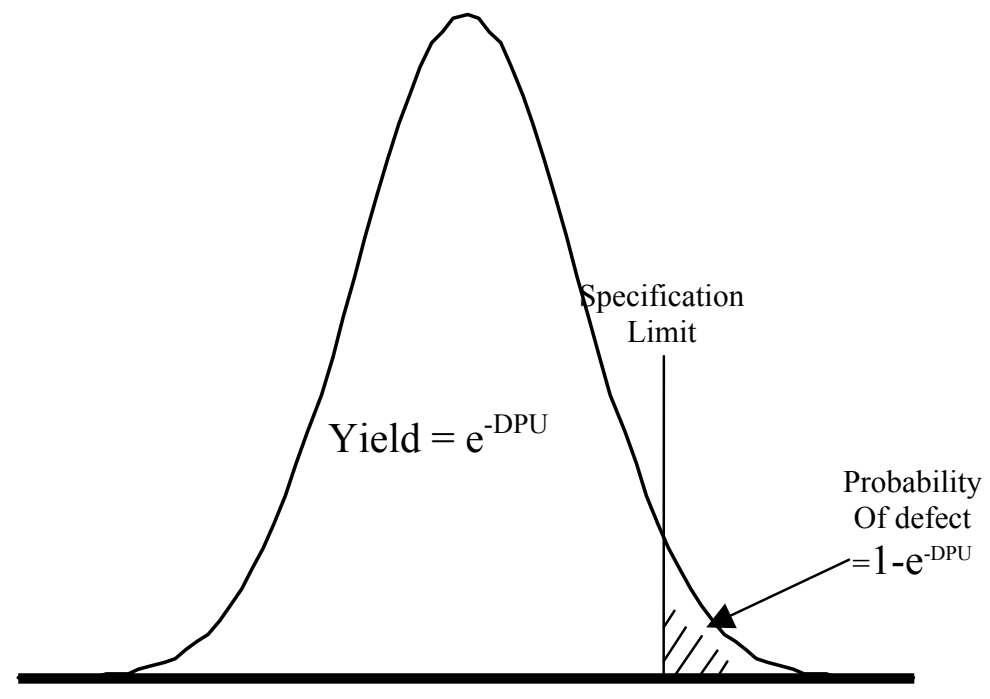

Figure 3. Normal Distribution, [3, p.139]

increases, the defect area to the right of the line gets smaller, hence the higher the sigma the less likelihood of a defect.

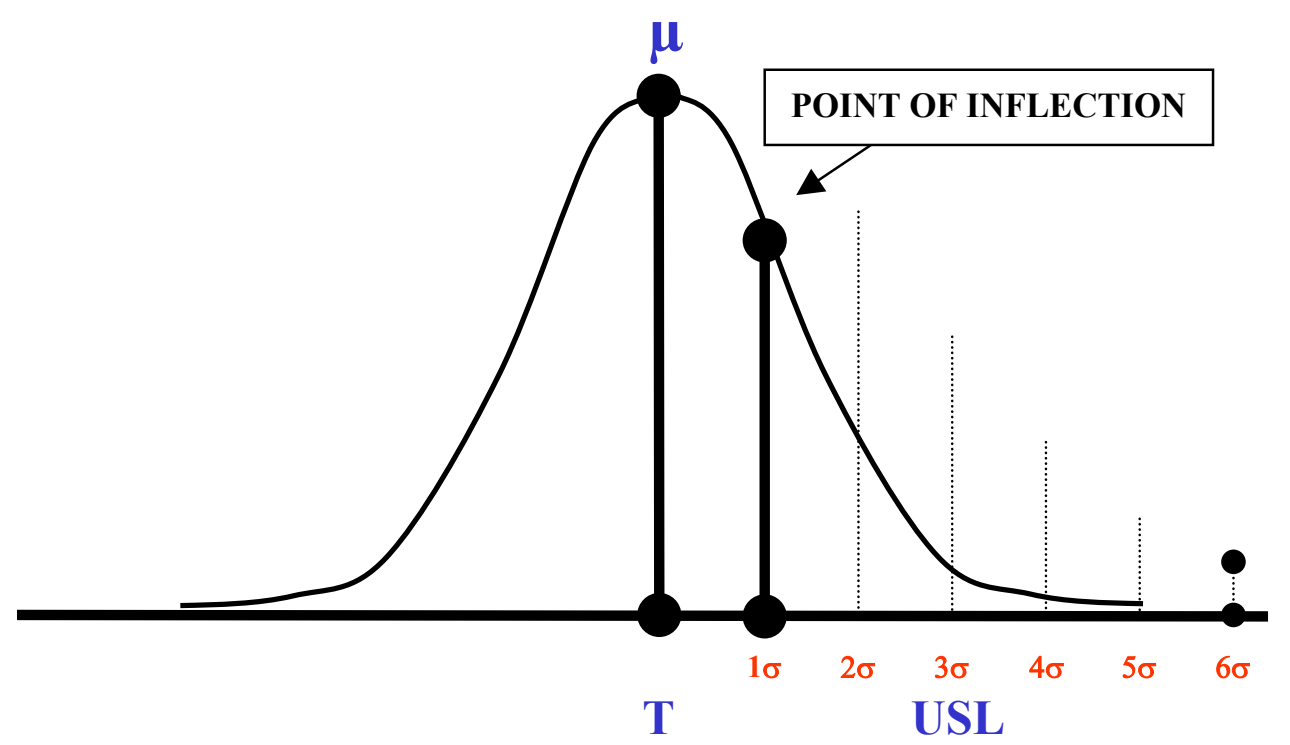

Figure 4. Sigma Relationship to a Normal Distribution

Table 1 shows the sigma value associated with the level of efficiency, measured in 
Defective Parts per Million Opportunities (DPMO).

Table 1.

Defective Parts per Million Opportunity

\begin{tabular}{|c|c|}
\hline$\sigma$ & DPMO \\
\hline & (Defective Parts per Million Opportunities) \\
\hline 2 & 308,537 \\
3 & 66,807 \\
\hline 4 & 6,210 \\
\hline 5 & 233 \\
\hline 6 & 3.4 \\
\hline
\end{tabular}

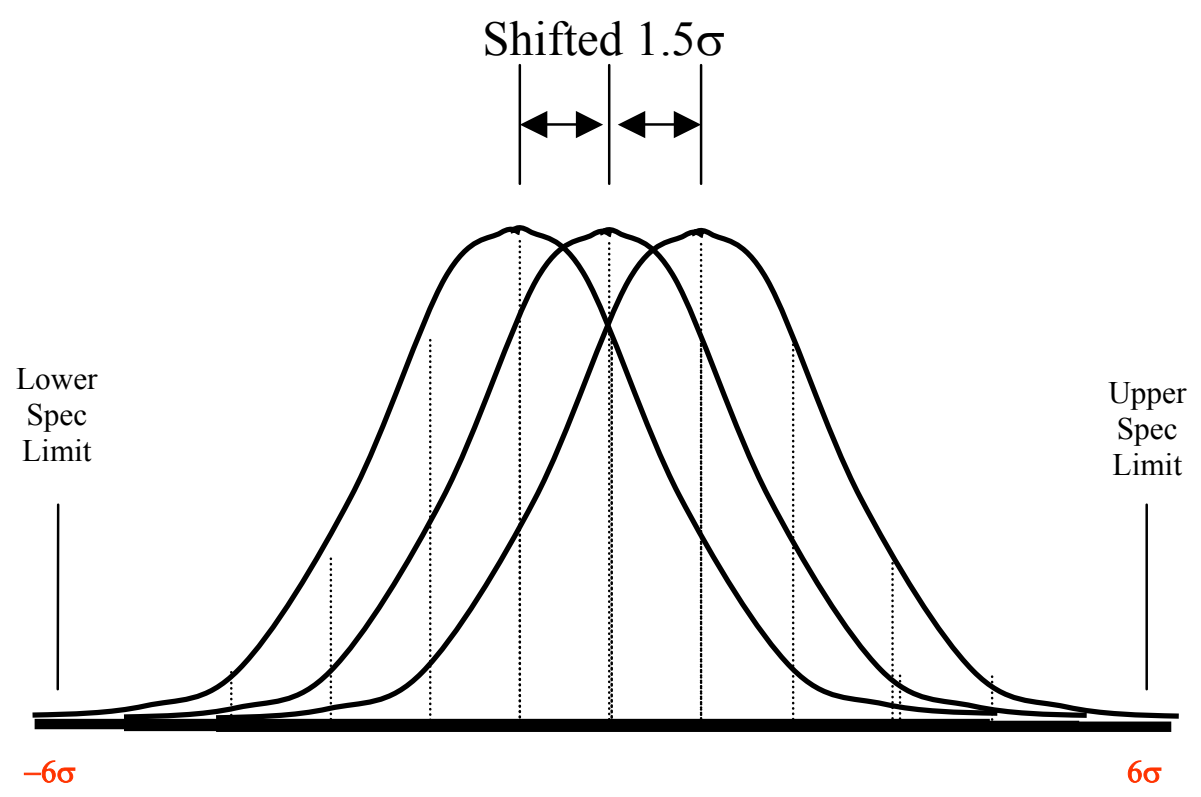

Figure 5. Effects of a $1.5 \sigma$ shift where only 3.4 ppm fail to meet spec, [3, p.10]

Would the average person settle for a 95\% confidence level that their airplane would not crash the next time they fly on a commercial airline? They probably would not, regardless of the price of the ticket. On the other hand, would that same person be 
willing to take a chance that they would be that 1 of 20 people who buy a light bulb and it burns out at 500 hours instead of the advertised 1000 hours, if it meant that they could get the light bulb at $\$ .50$ instead of $\$ 2.00$ ? There is generally a direct correlation between expected reliability, cost and consequences of failure. That 1 person out of 20 who buys the light bulb and it burns out early just buys a new light bulb. However, the person who gets on that 1 airplane that is going to crash, faces much greater consequences. From this example, it is easy to see why confidence intervals are so difficult to decide upon, because there is generally an added, up front cost associated with confidence intervals, as

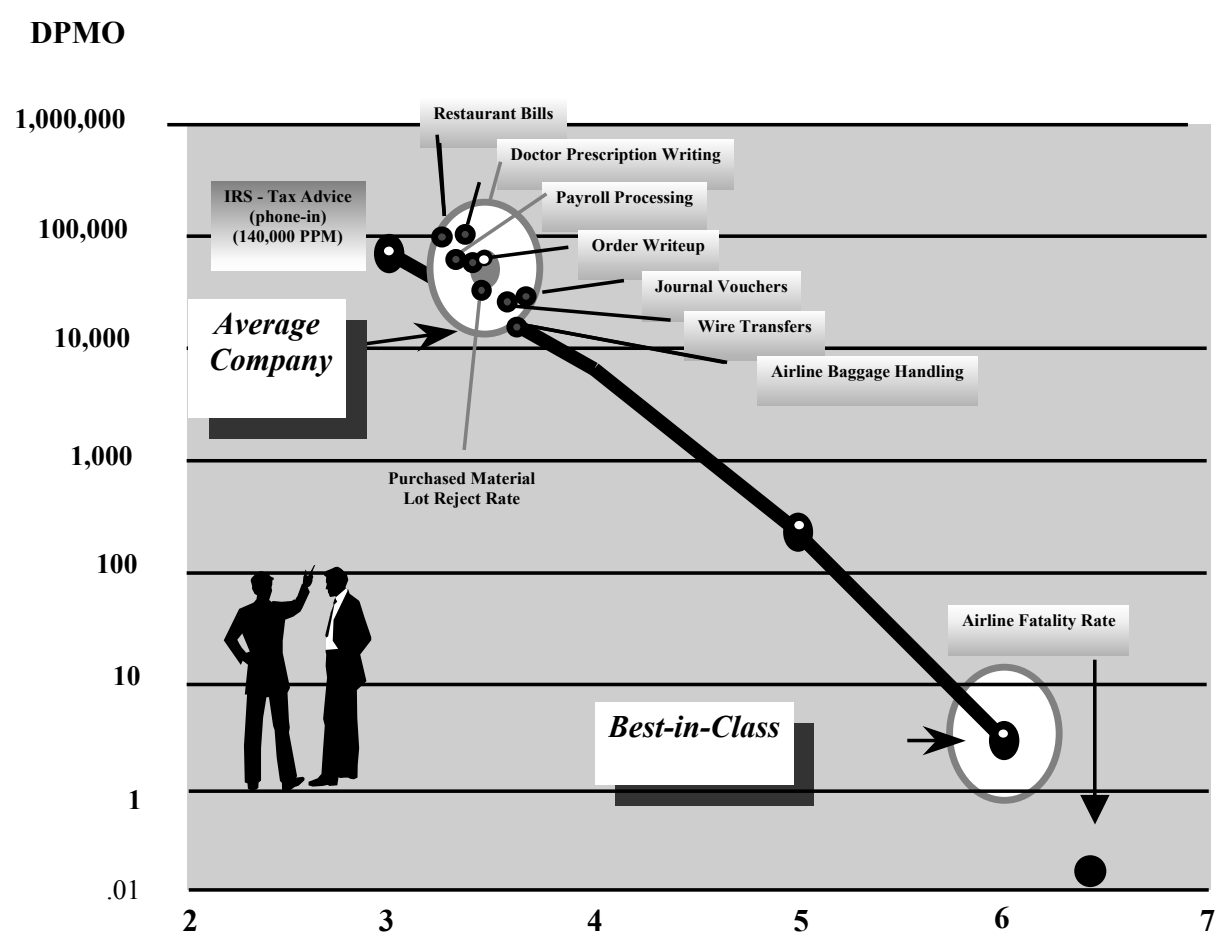

Figure 6. Sigma Rating per Industry, [27]

well as an added long-term cost. The aircraft industry is actually closer to seven sigma. In other words, the commercial aircraft industry has less than .43 fatalities per 1 million people who fly. They have to be that reliable because the average consumer would not fly and they would go out of business (not to mention the ethical issues). Certain 
industries are not so demanding and therefore will probably never achieve Six Sigma because it doesn't justify the cost associated with improving it to Six Sigma. Figure 5 shows some common industries and their respective sigma levels. So would this mean that Six Sigma doesn't apply to these industries? For such industries, it may not be feasible to go for the metric of six sigma, however, the methodology can still be applied for continuous improvement and to improve as much as is financially, or ethically, practical.

As an Initiative, Six Sigma is a method in which a business will drive its continuous process improvement program, utilizing traditional analysis tools as the fundamental common language. Six Sigma does not necessarily require any new statistical analysis tools or methods. It generally uses traditional quality tools in a very methodical approach to achieve improvement. A unique characteristic about Six Sigma as an initiative is that it organizes people and their thoughts. It synchronizes employees, engineers, managers, and leaders to communicate with a standard method of accomplishing improvement. When a business decides to implement a "Six Sigma Program" or initiative, they are committing to their employees that they are going to focus on long term improvements. It must be led from the top down through the organization. Use of the "Six Sigma Tools" is enforced, but first the employees must be trained to use them. Hours are spent in meetings, training, experimenting, and in front of a computer analyzing data. Implementing a Six Sigma program into a business is "a cultural change" according to former CEO of GE, Jack Welch. The larger the business the more monumental the task becomes. According to Welch, "The training costs are astronomical. In 
1997, GE will spend $\$ 400$ million on training. But it is counting on $\$ 600$ million in savings from Six Sigma improvements - for a net benefit of \$200 million" [25 p.60]. The historical standard for most manufacturing has been somewhere around three or four sigma. In other words, every one million items produced generates between $6,000-60,000$ defects. The variation is dependent upon the industry and there are exceptions. Six Sigma as a business initiative is no longer taken so literally as it began with Motorola, who eventually dropped their program as a failure because they could not achieve a point of only 3.4 DPMO.

As a Philosophy, Six Sigma does not focus on the metric but on the methodology. As a philosophy, Six Sigma is insisting that data drives decisions, almost to the point of being ridiculous. "Show the data" is a common phrase heard among Six Sigma "philosophers". There will always be a place for engineering intuition, but in a business that captures the Six Sigma philosophy, it should be the exception rather than the norm. Nearly all decisions are determined by what the data shows. It is not easy to gather data. However, Six Sigma philosophers always support, almost even insist, on data to drive their decisions. Even when discrete, objective data is not available, other methods like Brainstorming Sessions, Fishbone Diagrams, Cause-and-Effect Matrices, and FailureMode Effects Analyses are used to generate data with which to work. Six Sigma "philosophy" is simply using methodical means for achieving logical solutions to drive business decisions.

\section{Motorola}

Motorola introduced Six Sigma in the mid 1980s, as they were being severely impacted by Japanese competitors. Leaders within Motorola had concluded that the 
quality of their products was very poor. A new initiative derived from Motorola's Communications Sector tracked performance by a sigma metric. Company CEO, Bob Galvin, initiated the "Six Sigma Quality Program" at the managerial and organizational levels, driving a zero-defects mentality through all facets of the organization - processes, products, services, and management. Galvin insisted on Total Customer Satisfaction (TCS) by improving on-time delivery, order completeness, order accuracy, and improved product quality. In return for this quality improvement, it was suggested that his business would receive a 5\%-20\% increase in business from many customers. The program was taken very seriously. The Motorola Corporate Policy Committee updated the company's quality goal to the following:

Improve product and services quality ten times by 1989 , and at least one hundred fold by 1991. Achieve Six Sigma capability by 1992 . With a deep sense of urgency, spread dedication to quality to every facet of the corporation, and achieve a culture of continual improvement to assure Total Customer Satisfaction.

...one ultimate goal: zero-defects - in everything we do. [4]

Motorola turned the business around with this new initiative. By 1988, Motorola won the first Malcolm Baldridge National Quality Award, presented by the US Congress for recognition of high quality standards in American Business. Along with their success came a newly invented concept, which was eventually accepted by GE and other businesses and has evolved into a comprehensive quality management system.

\section{Honeywell/Allied Signal}

Allied Signal (now Honeywell) began their program in the early 1990s when their CEO realized the effect Motorola's program had on it's business. They applied the methods and tools to reducing cost of rework, but they also implemented the 
methodology into design of their products. Designing quality into products is no new concept either, but Design For Six Sigma (DFSS) again forces methodical, data driven approaches to design.

\section{$\underline{\text { General Electric }}$}

General Electric CEO, Jack Welch, drove the program through General Electric beginning in the mid 1990s. He still considers Six Sigma as one of GE's greatest initiatives, one of which they are still improving and driving throughout all GE businesses. While Motorola began a Six Sigma initiative to save the business, GE was already prospering and had been for years. So why would GE take on an initiative like Six Sigma? It is all about change.

Six Sigma has forever changed GE. Everyone - from the Six Sigma zealots emerging from their Black Belt tours, to the engineers, the auditors, and the scientists, to the senior leadership that will take this Company into the new millennium - is a true believer in Six Sigma, the way this Company now works." GE Chairman John F. Welch. [5, p4]

GE took the model from Motorola and Allied Signal, and began learning, training, and enforcing use of the methodology within the company. Goals were set, such as being a Six Sigma Company within 5 years. Demands of leadership involvement were enforced all leaders were to be trained in Six Sigma methodology. Furthermore, individual leader involvement would be a primary metric for annual reviews, salary actions, bonuses, stock options, and all other benefits. Even today, all salaried employees have to become Six Sigma Certified in accordance with the standards of the General Electric Six Sigma Certification Program. Without certification, individuals will not receive salary actions or positive annual reviews. There is no choice if a person wants to work at GE. This 
kind of "lunacy", as Welch put it, is exactly the kind of leadership required when taking on this initiative and expecting results. Results were achieved. GE Medical Systems (GEMS) used Six Sigma to help redesign their medical scanning technology and reduce the amount of time it takes to conduct full-body scans. Furthermore, GEMS has increased the expected life of their CT scanner x-ray tubes 10X, again through design improvement (Design For Six Sigma - DFSS). GE Lighting (GEL) has made numerous process improvements and improved service with their biggest customer, Walmart, by reducing customer issues by $98 \%$. GE Power Systems (GEPS) mended relationships with their utility customers by using Six Sigma to develop a better understanding of their requirements. These are just a few examples within GE. General Electric's newest endeavor is to force it deeper into the organization. Within GE, Six Sigma has gone from a nearly separate, autonomous group to an organization that is blending more and more with the manufacturing, engineering, and sales teams. Black Belts are no longer looked at as these outside, individual, process optimization gurus. They are team members, blending in with the daily operations. Most of the business leaders, starting at the plant manager level, are past Black Belts or Master Black Belts.

\section{Other Programs}

Other companies that have implemented successful Six Sigma programs including Sony, Bombardier Transportation, Asea Brown Boveri, Lockheed Martin, and 3M. This list is by no means inclusive. As some of the aforementioned companies and others have started their programs, they claim to have achieved the monetary benefits in Table 2 within the first several months of implementation. 
Table 2.

$\underline{\text { Initial Savings }}$

\begin{tabular}{|l|c|c|}
\hline Company & Savings & Duration \\
\hline Allied Signal & $\$ 1.2$ billion & 2 years \\
\hline General Electric & $\$ 1.1$ billion & 9 months \\
\hline Polaroid & $\$ 100$ million & 1 year \\
\hline Lockheed Martin & $\$ 10$ million & 9 months \\
\hline Siebe PLC & $\$ 100$ million & 9 months \\
\hline Crane's & $\$ 10$ million & 1 year \\
\hline
\end{tabular}




\section{CHAPTER III}

\section{THE PROGRAM}

\section{$\underline{\text { Overview }}$}

As stated before, a Six Sigma initiative is a method in which companies drive continuous process improvement- setting up an infrastructure, training their teams on standard analysis tools, and driving a program of customer centricity, data analysis, and control plans throughout their business. A company that is serious will always begin with the highest-level manager. Six Sigma is an initiative that will not survive unless it is completely supported by the highest levels of management and driven down through the organization.

So the first step is training and buy-off from higher management. Companies will generally do this by sending their senior managers to some type of a retreat, or workout, ranging from days to weeks. During this time, they will learn the methodology and higher-level implementation of Six Sigma as it applies to business strategy. It will involve lots of team building, role-playing, and hypothetical discussion and analyses. The main purpose is to ensure that everyone who is going to be driving this program through the business understands the capabilities and believes in the potential results for the business. Then those leaders will actually learn the basic tools and execute simulated projects, or case studies. It is not critical, although helpful, for the higher-level managers to understand all of the tools. It is critical, however, for them to understand what the 
capabilities and limitations are.

The second step is to train the full-time Black Belt team, Black Belts and Master Black Belts. This is also usually done by a professional consultant. There are several consulting companies that specialize in Six Sigma training at all levels. The list below is by no means inclusive.

\section{$\underline{\text { Organization }}$}

The Six Sigma Academy

Advanced Systems Consultants

Six Sigma Qualtec

\section{Web Site}

www.6-sigma.com

www.mpcps.com

www.sixsigmaqualtec.com

Once the higher-level managers and Six Sigma team are trained, a company should have enough knowledge to start training their personnel internally. Consulting fees are quite expensive. Some businesses even try to lure formally trained Black Belts and Master Black Belts away from their companies to start new programs. The greatest risk in doing this is credibility. Companies need to be sure they are getting quality training in order for the program to be successful. Consulting firms are beneficial initially, until a company just starting out builds a foundation of knowledgeable leaders. However, eventually as the company grows it is more beneficial to train from within the company. One technique is to graduate into an internal training program. Train the upper-level management first through formal means. Then, send the Black Belt team to formal training. While the Black Belt team is at their training, the upper-level managers can be looking at their independent areas for opportunities. When the Black Belt team returns, they can immediately begin projects. Project team members do not necessarily all have to be formally trained up front, however it is a good long-term goal. Leaders who 
understand Six Sigma methodology should be leading project teams. As the projects begin to take shape and the pace slows down for the Black Belts, then the company can gradually begin to train their mid-level key leaders and engineers through an internal training program, which should be led by the Black Belt team. The key is to get as many people trained in the tools as possible. The internal training can be tailored to the business needs. It does not have to be as long and drawn out as the consulting training.

The initial investment in consulting fees and training time required of key leaders is often enough to discourage businesses from initiation of a Six Sigma Program. Some businesses have succeeded and some have failed. If a company wishes to make the program a success, it requires total commitment, some risk, and quite a bit of up front money for training.

\section{$\underline{\text { Infrastructure }}$}

Six Sigma teams have several levels of responsibility. Some companies choose to keep their Six Sigma Black Belt team as a separate organization while others want the Black Belt team integrated into the organizational teams, ie Manufacturing, Sales, IT, etc. No matter what method is used, there are certain positions that must be present in order to have a successful program.

A Six Sigma Champion is usually assigned as a part-time additional duty to the top performing business leaders. Champions will mentor those who guide the projects, in relation to the business strategy. They mentor the entire team of Master Black Belts, Black Belts, and Green Belts and guide them so that the Six Sigma projects will stay focused on the needs of the customer and/or business. Champions also drive the overall Six Sigma program and commitment throughout the business at higher echelons. They 
also resource the program, at all levels. They communicate in business terms what impact Six Sigma is having and they coordinate project report-outs to higher-level management. They must be trained on the basic tools and understand the methodology, but a Six Sigma Champion's true mission is to drive the program throughout the business - change the culture. Therefore, a Champion must fully understand and believe the philosophy. "Champions... successfully organize and effectively lead the deployment of Six Sigma across a large organization." [2, p.24.4]

Master Black Belts $(M B B S)$ are full-time Six Sigma "experts" who are responsible for implementing Six Sigma methodology at the site level. They act as the liaison between the site team and the Champions, helping to resource the teams and knock down any roadblocks that are preventing project execution. They are usually highly involved with ensuring the team members are properly trained and certified. They mentor and guide Black Belts, enforcing good communication with site managers. MBBs coordinate for periodic site reviews with the Champions. They will often manage more than one site and oversee many Black Belts. They personally mentor Black Belts on their projects, both in the project management role and at the technical level. They are accountable to the Champions for achieving annual goals. Often, MBBs are past Black Belts. Although it is not required, this technique helps the MBB understand what a Black Belt is facing during project completion.

Black Belts $(B B S)$ are the highest level at which projects are executed. They manage large-scale projects that are generally made up of many smaller projects. They coordinate and administrate all team activities, assigning tasks to team members. Black Belts track the team's goals, progress and benefits. They are the project executors and 
internal site trainers. They are generally made up of a company's top-performing salaried employees. They are leaders. Black Belts generally have no command authority like other managers, so they have to lead through influence. This difficult task is just one reason a company should insist on the "crème-de-la-crème". If a company invests money in only one area, this is the place they should do it. They are by far the closest team members to the improvement projects and are the ones who are going to drive them to completion. A Black Belt understands business metrics and sees the "big picture". They must be well versed in the tools but they must never become tunnel-focused. It is critical that all Black Belts do not let boundaries get in their way, always thinking "outside of the box". Black Belts are the main driving force that ultimately determines whether or not projects are completed on time and on budget.

Green Belts $(G B s)$ are formally trained employees who work as project team members, or leaders, while maintaining their normal duties ie. engineers, managers, supervisors, etc. Green Belts can be hourly or salaried. They usually take on projects of a smaller nature, both in scope and benefit. A robust Six Sigma program will organize their teams so that Green Belts are supporting projects that Black Belts are working on in the same area/department. This encourages synergies between GBs and their BB Mentors. The Black Belts will manage the larger, umbrella projects and the Green Belts will tackle smaller targets that fall under the umbrella projects. Green Belts are also accountable for their own project completion and annual benefit accomplishments. They are generally mentored by whatever Black Belt is supervising the umbrella project under which their project aligns.

Yellow Belts (YBs), also called Associates, are employees who have not been 
formally trained on all of the Six Sigma tools, yet they have a working knowledge of the Six Sigma methods and tools. They have probably received a modified version of Green Belt training. They usually are not leading a project themselves (unless very limited scope), but at the same time they are key team members with the technical expertise that is critical to successful completion of a project. They are generally matched to projects inherent to their work areas. Associate positions are critical to Black Belts and Green Belts during project execution.

\section{Project Identification, Organization and Execution}

The Six Sigma Methodology is nothing new to most technically trained people. It is simply a very methodical, organized, team approach at solving problems and improving processes. It follows a Define, Measure, Analyze, Improve, Control format. Prior to beginning the DMAIC process, projects must first be identified and assigned.

At the end of each fiscal year, site managers begin planning for the following fiscal year business plan. This Operating Plan (OP) includes expected opportunities in process improvements, to include Six Sigma. A Six Sigma project will formally be approved or disapproved by a Champion, MBB, and site manager. Ideas for projects are conceived by anyone, from business CEOs to subcontractors. No matter who comes up with the idea for a project, it must be carefully analyzed and determined whether or not it is going to be beneficial. Leaders must determine timeliness, cost, savings, resources required, benefit to the customer, and any other facet inherent to the project scope. Site managers usually formulate Six Sigma benefits into their normal Operating Plan. Champions and MBBs will formally analyze most projects to ensure that they are meeting the customer needs and that they offer some sort of benefit to the organization. The benefit is generally 
monetary, however, sometimes project benefits are measured by non-quantitative means. For example, a project could be focused on fixing a process that will improve machine speed by 3 indexes per hour (definite monetary benefit) or it could be to improve the facility's safety training program (no direct monetary benefit to the facility but possible long term cost savings to the company). Regardless, the need for a project is identified usually through normal business analysis procedures ie. a department is missing on-timedelivery, or a particular machine group is only achieving $75 \%$ yields. These issues are usually formally brainstormed at the site level during some annual review (minimum) that involves the MBB, site managers/leaders, all BBs, GBs, and maybe select YBs. The key projects (usually the greatest or quickest benefits) are prioritized and assigned to Black Belts. These key projects will have smaller level projects that support them, which will usually be assigned to a Green Belt or maybe even an Associate. Any smaller scope projects that have not been covered will be assigned to Green Belts. This process will usually take place in the third or fourth fiscal quarter to ensure communication to all participants prior to fiscal year end. Once the annual project/benefit plan has been established, key leaders will review it with their respective departments and teams will be formed.

The first step of project execution is to Define the Problem. Usually not considered a time consuming portion of the project, here you are simply defining exactly what is going to be addressed, or improved upon, from a very high level and referred to as the "Big Y" (this term derived from an xy plot where "y" is the desired result). The mistake that most new project leaders make is they execute this process too quickly because they are anxious to start measuring data. Data collection is important, however, it is critical that 
the scope of a project is very clearly defined in order to optimize the potential of the team. There are many people involved with making a Six Sigma project successful, and all of those people need to understand very clearly what the full scope of the problem is. A key first step in this process is identifying valuable team members. Deciding who will be the leaders, who will be critical team members, and who will simply be needed to support the project is critical. All of these people will meet for an initial brainstorming session to define the full scope of the problem. There may be more to the issue than what was initially thought. With the assistance of all team members, the end result should be to identify issues outlined in Table 3.

Table 3 .

Define The Problem

\begin{tabular}{|l|l|}
\hline Topic & Description \\
\hline Team members & who is needed to make this project successful \\
\hline Customer & who is the customer, both internal and external \\
\hline Macro statement of the problem & 10,000 foot level \\
\hline Micro statement of the problem & details, details, details \\
\hline Critical To Quality (CTQ) & metrics on which you are trying to improve \\
\hline Output & defects or characteristics which need focus, to improve CTQs \\
\hline Inputs & what factors may impact the CTQs \\
\hline Data type & what types of data will be needed \\
\hline Data source & how/where will the data be collected \\
\hline Time & estimated time to complete project, beginning to end \\
\hline Projected benefits & expected end result of this project (be conservative) \\
\hline Customer expectation & what is the customer expecting from this project \\
\hline Risks & things that could affect how well the project is executed \\
\hline Translation & has this or something similar already been done and/or could someone \\
use this after I am finished
\end{tabular}

During the Measurement phase, the Six Sigma team gathers data. Some forms are in a simple manual data collection sheet like the one in figure 4 below, while others are much more sophisticated and usually involve some form of computer software package such as Cimplicity or Oracle, just to name a few. 
Table 4.

$\underline{\text { Sample Data Collection Sheet }}$

DATE:

Downtime Codes

\begin{tabular}{|c|l|c|l|}
\multicolumn{5}{|c|}{ Downtime Codes } \\
\hline Code & \multicolumn{1}{|c|}{ Reason } & Code & \multicolumn{1}{c|}{ Reason } \\
\hline 1 & Accumulator Full & 11 & Pick and Place \\
\hline 2 & Bulb Conveyor \& Transfer & 12 & Reflector Conveyor/ Transfer \\
\hline 3 & Cementers & 13 & Sensors/ Eectronics/ Series Six \\
\hline 4 & Changeover Setup & 14 & Six Sigma/Engineer Test \\
\hline 5 & Eectrical Wiring & 15 & STA 10 \& STA 23 Errors \\
\hline 6 & Heads & 16 & STA 7 Rejects \& STA 8 Nest \\
\hline 7 & Heat Lamps & 17 & Startup/ Shutdow $\mathrm{n}$ \\
\hline 8 & Miscellaneous (All Others) & 18 & Unload Transfer \\
\hline 9 & Nest Opener & 19 & Vision/ Zenith/ Align \\
\hline 10 & Overhead Units and Neat & 20 & Wire Lamp Feed \\
\hline
\end{tabular}

\begin{tabular}{|c|c|c|c|c|}
\hline \multicolumn{3}{|c|}{ Downtime } & \multirow{2}{*}{$\begin{array}{c}\text { Reason } \\
\text { (use above codes) }\end{array}$} & \multirow[b]{2}{*}{ Remarks } \\
\hline Start Time & End Time & Minutes & & \\
\hline & & & & \\
\hline & & & & \\
\hline & & & & \\
\hline & & & & \\
\hline & & & & \\
\hline & & & & \\
\hline & & & & \\
\hline & & & & \\
\hline & & & & \\
\hline & & & & \\
\hline & & & & \\
\hline
\end{tabular}

Regardless of the method of data gathering, the user must ensure the data is as accurate as possible. This data is what will eventually be used to analyze the troubled area and formulate a solution to improve the process. So this is a critical part of any project. If something is found to be questionable, the data collection systems should be tested formally for accuracy. This is done by creating data sets and running them through the data collection system and then reviewing it to see if it generates the expected results. This is called a Gauge $R \& R$ and is one of the tools that will be reviewed in a later chapter. Once the data collection system is validated, it is safe to begin data collection, however, throughout the entire project the accuracy of data should constantly be scrutinized. 
Analysis of the Data is where the real statistical work will be done and where most of the mistakes in projects are made. The key to data analysis is not just knowing how to use the statistical analysis tools, but when to use them. A technique for becoming proficient at this tool usage is to read books and reference them often. Some businesses develop "road maps" for tool usage. The references outlined at the end of this thesis are a good start, but by no means inclusive. Once the analysis is complete, it is sometimes desireable to have another person review the data and analysis. This can foster new ideas. Other than the final review, where the analyst may want a second opinion, analysis can pretty much be done alone. The analysis tools are already established (and have been for years). If the analyst does not know the tools, though, this process can lead to complete failure in the project. Some analysis tools are touched on in Chapter IV of this thesis. If correctly analyzed, the data analysis will generally point the team in the right direction to improvement.

Once again, it is time to get the team together to figure out how to Improve the process, based on the analysis results. This is where the term "out-of-the-box" thinking is key. The question must always be asked, "what is the bottom line?" The bottom line may be to reduce cost, maintain the best quality, or simply to do what is right. Companies keep customers by delivering quality products to them on time and at a reasonable price. But that's not it. All of this can be done and a company can still go out of business. Businesses have to turn enough profit to cover costs and generate revenue. If they aren't doing that, then they won't be in business for long. So the team must constantly be thinking creatively how to improve the process, based on whatever the data is pointing them to, and ultimately saving the company money. If the process is 
improved but it costs more than the savings can justify, then that company will not be in business for long. The recommended approach for improvement is brainstorming. Get as many different types of people in a room and show them the data analysis. One should not underestimate the value an hourly operator can add during brainstorming sessions, to help resolve major process issues. The meeting facilitator should hold back nothing, invite ideas from everyone, and encourage people to think outside of the box.

While improving a process takes a lot of creativity, Controlling a process is pretty straightforward. There are two primary factors to process control - effective control systems (ie Manufacturing Control Plans, Manufacturing Process Instructions, Statistical Process Control, etc) and discipline. Some of the aforementioned controls will be defined in a later chapter. Control systems should be consolidated within the Quality Assurance department and should become part of the overall quality system for the facility. Control systems can be very simple to very complex. Many control systems today integrate complicated computer management systems or computerized Statistical Process Control. Other control systems are on a clipboard and updated with a pen. Either way, the most important aspects are that they work (ie when properly used do they keep the process in control) and do the employees using them understand how to use them. If these two factors are in place, then the only other issue is are they actually being used to maintain control. This can be audited on a regular basis, even included in an ISO facility's internal audit program. Control is generally viewed as the most important portion (if there is such a thing) of the DMAIC process, because it will determine whether the improvement continues in the future. Unfortunately, it is the step that is most commonly overlooked. If not careful, a team can be so busy celebrating after they 
have improved a process, they can completely forget about control, and within no time the process is back to the same poor standards as before the project began. 


\section{CHAPTER IV}

\section{TOOLS}

\section{$\underline{\text { Define }}$}

Brainstorming is nothing more than a meeting of people who may have knowledge on a subject to be discussed. The purpose is to come up with ideas around the subject. Brainstorming can be used to solve problems, create fishbone diagrams, come up with ideas for solutions, etc. This tool is a very important part of any problem-solving technique. It should be used throughout a Six Sigma project to gather information and create new ideas. A facilitator should keep the meeting on track. Ground rules should be established in the beginning of the meeting to encourage "out of the box" thinking and to discourage personal attacks or negativity.

The Process Map, Fig is a method of flowcharting processes. It is a graphical tool that shows what the flow is of any procedure. Generated during the early stages of a Six Sigma project, effective Process Mapping can explain to anyone how the system works. All projects should construct Macro-level and Micro-level process maps to use throughout the project for reference, explanation and analysis. 


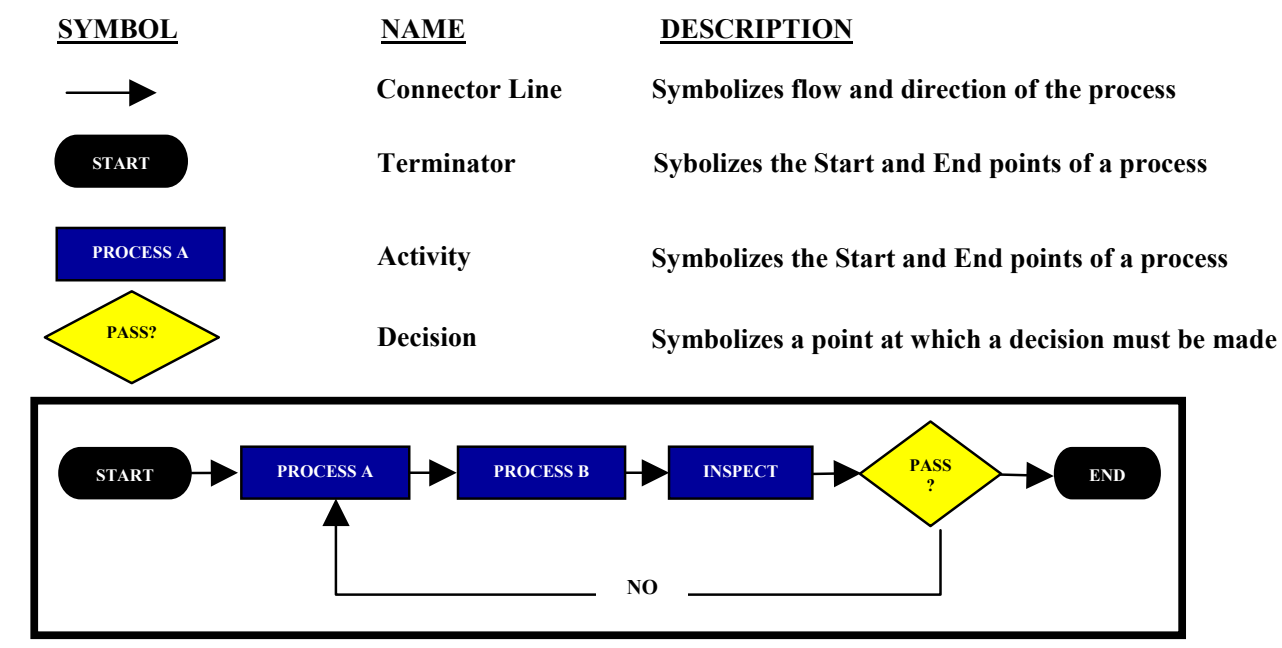

Figure 7. Process Map

Rolled Throughput Yield (RTY) focuses on a defect rate throughout a process rather than at the end of the process, and may be calculated by the formula in Figure 8 .

$\mathbf{R T Y}=\mathbf{Y}_{\mathbf{R T P}}=\mathbf{e}^{-\mathbf{D P U}}$
$\mathrm{Y}=$ =yield
RTP=Rolled Through Put
$\mathrm{e}^{-\mathrm{DPU}}=$ probability of units with zero defects

Figure 8. Rolled Throughput Yield Formula, [3] p.137

If an organization focuses just on the end defect rate, it will lose site of all of the wasted effort throughout the process. RTY is a method of breaking down where different amounts are lost throughout a process. Rolled Throughput Yield can also be depicted graphically as in Figure 9. 


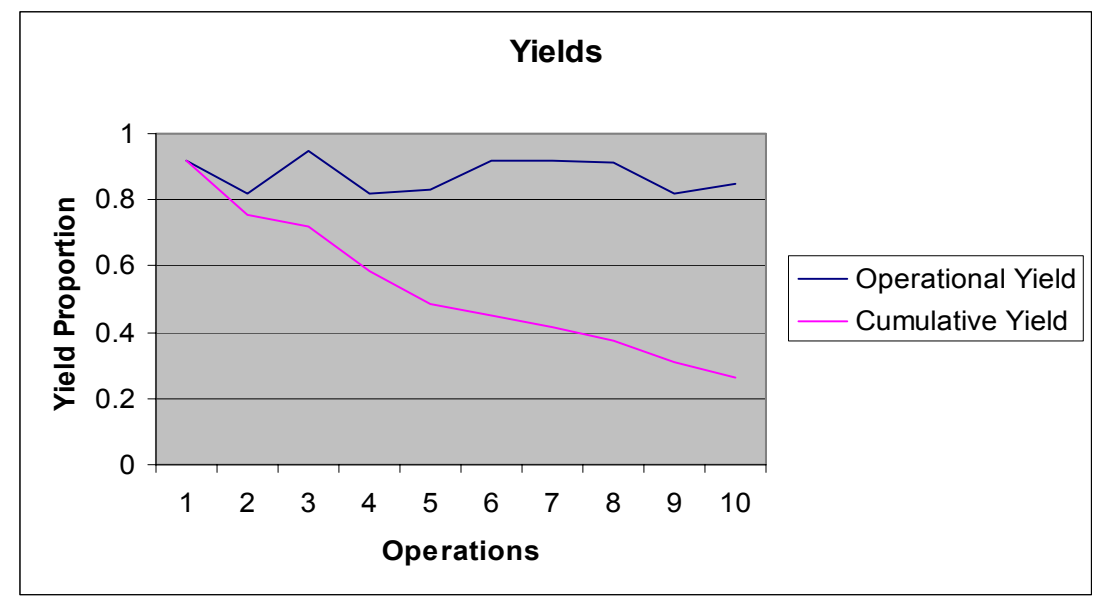

Figure 9. Rolled Throughput Yield

\section{$\underline{\text { Measure }}$}

Gage Repeatability and Reproducibility (Gage $R \& R$ ) is a method of evaluating measuring systems and should be used throughout a Six Sigma project to check the validity of measurements.

Gage repeatability and reproducibility studies determine how much of your observed process variation is due to measurement system variation. Any time you measure the results of a process you will see some variation. This variation comes from two sources: one, there are always differences between parts made by any process, and two, any method of taking measurements is imperfect - thus, measuring the same part repeatedly does not result in identical measurements [30, Gage R\&R).

$$
\sigma_{\text {error of measurement }}^{2}=\sigma_{\text {repeatability }}^{2}+\sigma^{2} \text { reproducibility }
$$

Figure 10. Gage Repeatability \& Reproducibility

Gage $R \& R$ is used to measure both accuracy of measuring tools and the precision of the people using the tools. Basically, a gage $R \& R$ is conducted by running samples of parts 
with known values through multiple tests and yielding results. It is critical that inspectors do not know what the correct measurements are until after the tests are completed. Gage R\&R tests may be run without any inspectors even knowing it is being done, to eliminate the possibility of them changing their normal routine and potentially skewing results.

Process Capability/Performance Study is used in the initial phase of a Six Sigma project to baseline where the process is at that particular time and to determine the potential of the process.

Minitab has a function called Process Six Pack which is effective in conducting a quick Process Capability Analysis which will produce Xbar R charts for Mean and Range, Subgroup charts, Capability Histogram, Normal Probability Plot, and a Capability Plot all in one graph.

Process Capability Analysis for Process X

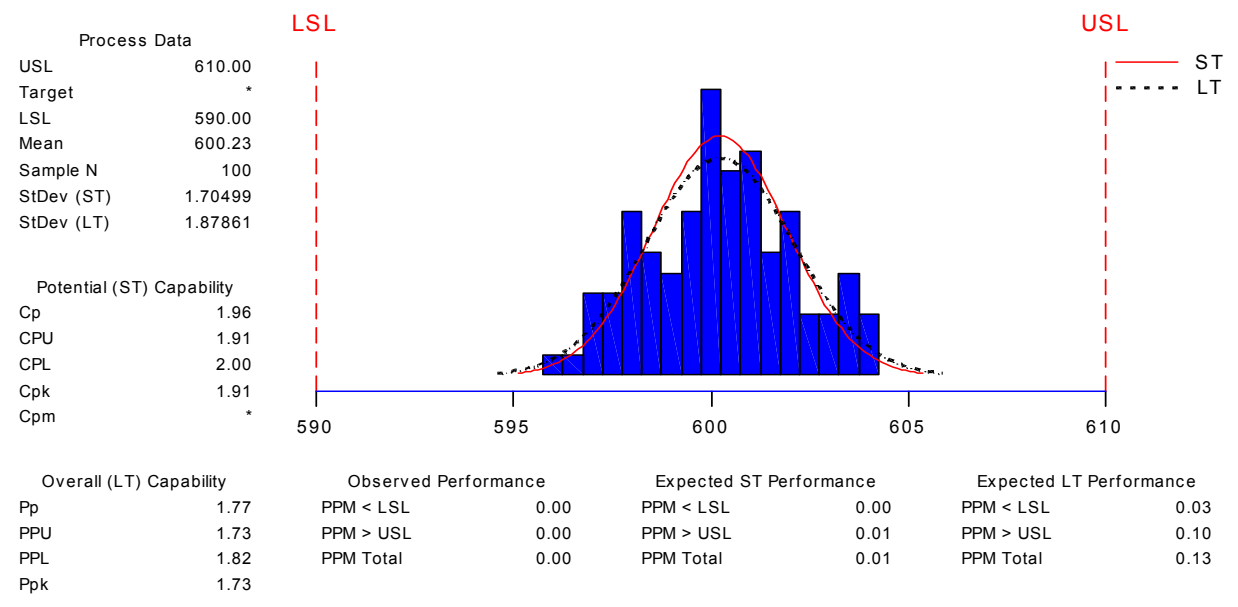

Figure 11. Process Capability from MINITAB 


\section{Process Capability Sixpack for C1}
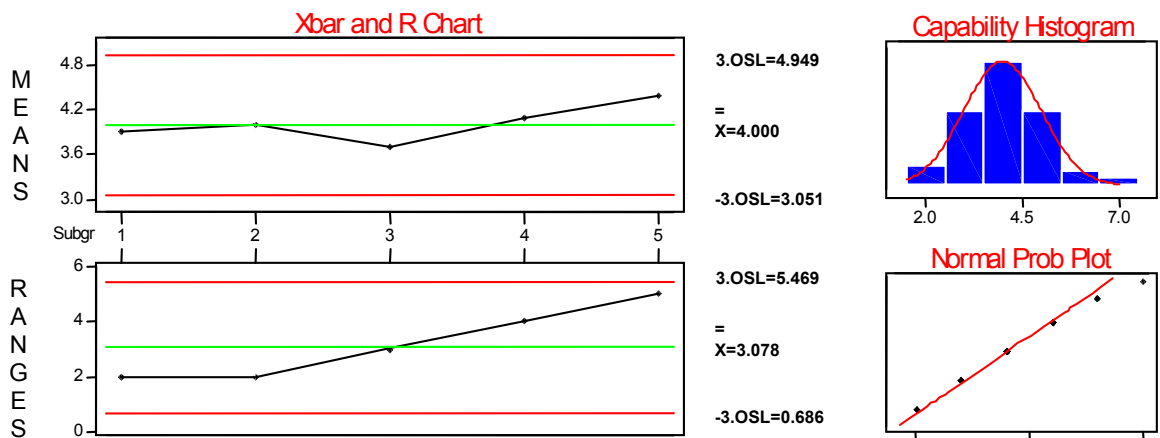

$3.0 S L=5.469$

$=$
$X=3.078$

$-3.0 S L=0.686$

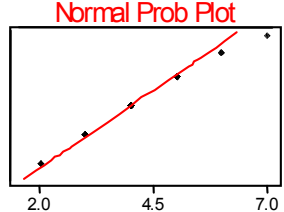

Potential (ST

StDev: 1

Cp: 0.33

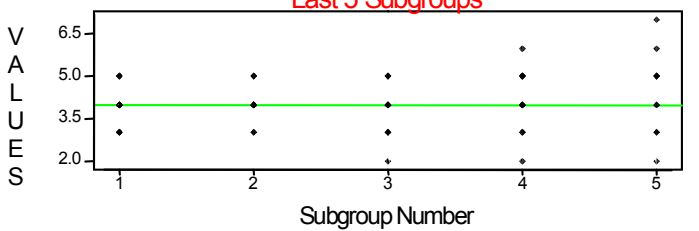

pk: 0.33

Overall (LT)

StDev:

1.04514

$\begin{array}{ll}\text { Pp: } & 0.32 \\ \text { Ppk: } & 0.32\end{array}$

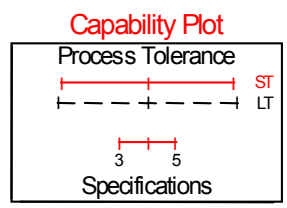

Figure 12. Process Capability Sixpack from MINITAB

The Fishbone Diagram (also called a Cause and Effect Diagram) is a tool used to identify input variables that impact the Key Process Output Variable (KPOV). This technique can be used for any process. A fishbone diagram is a precursor to creating a Cause and Effect Matrix. The KPOV is recorded at the head end of the fishbone. The ribs depict six factors of discussion - Environment, Materials, Methods, Measurements, Machine, and Human factors. The purpose of the fishbone diagram is to get ideas onto paper. After the fishbone is completed, the person who called the meeting will take the diagram and organize it into a Cause and Effect Matrix, so it is not important to be organized or "final" while creating a Fishbone Diagram. The important thing is that all ideas are captured. 
MACHINING OF PART A

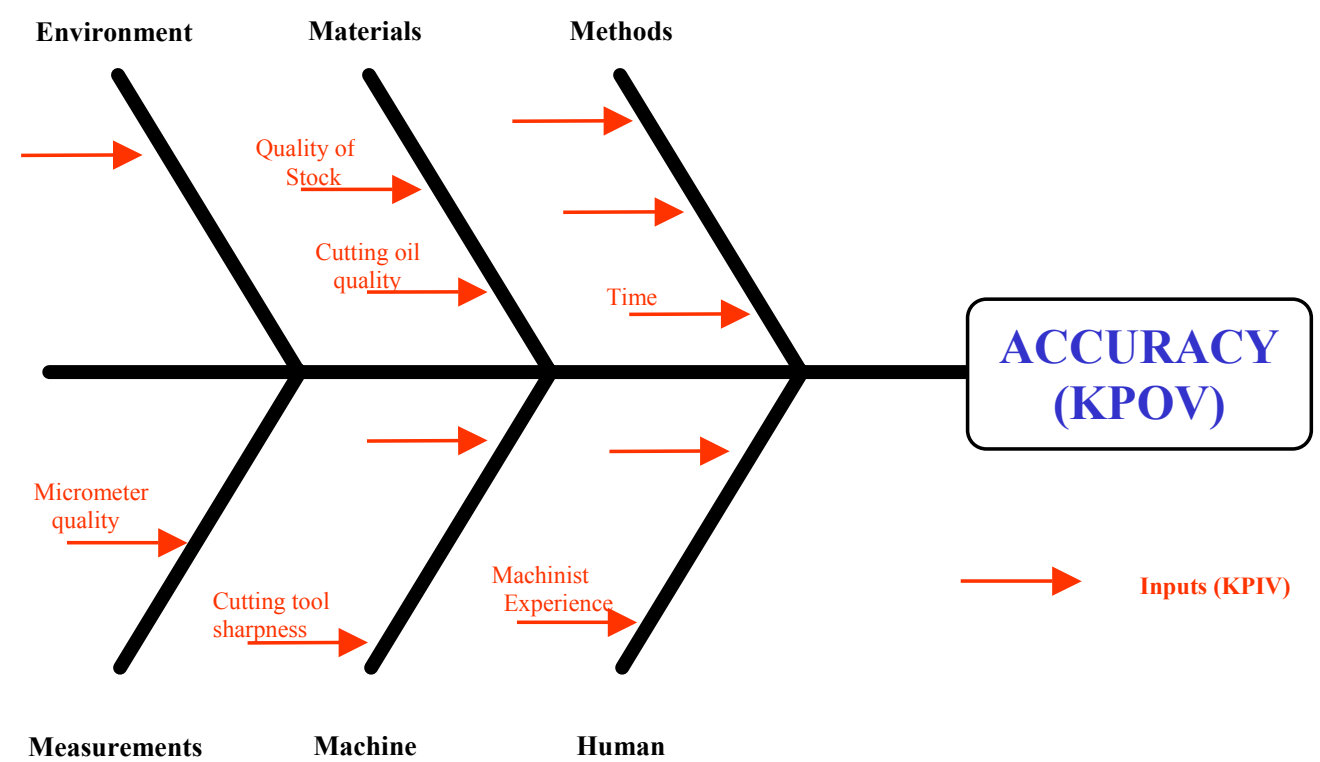

Figure 13. Fishbone Diagram

\section{$\underline{\text { Analyze }}$}

The Cause and Effect Matrix is constructed after the Fishbone Diagram has been created. Input variables are assigned values in terms of what effect they will have on the Key Process Output Variable (KPOV). Again, team members who are especially close to the process and understand the impact of each input variable should assist in assigning these values. Output variables are also assigned values based on the impact they have on what is important to the customers' Critical to Quality (CTQ) requirements. The most important input variable that should be considered, as a general rule of thumb, is the highest number in the far right-hand column. This would be identified as a Key Process Input Variable (KPIV). 


\begin{tabular}{|c|c|c|c|c|c|c|c|c|c|c|c|}
\hline \multicolumn{12}{|c|}{$\begin{array}{c}\text { CAUSE AND EFFECT MATRIX } \\
\text { Machining of Part A }\end{array}$} \\
\hline & \multicolumn{10}{|c|}{ OUTPUT VARIABLE AND VALUE (1-10) TO CUSTOMER CTQS } & \multirow[b]{3}{*}{ TOTAL } \\
\hline & 7 & 5 & 10 & 6 & & & & & & & \\
\hline INPUT VARIABLES/VALUE (1-10) & 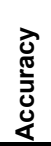 & 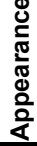 & $\begin{array}{l}n \\
\frac{n}{2} \\
\frac{0}{3} \\
\frac{1}{\pi} \\
\frac{1}{0}\end{array}$ & 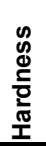 & & & & & & & \\
\hline sharpness of cutting tools & 10 & 0 & 8 & 0 & 0 & 0 & 0 & 0 & 0 & 0 & 150 \\
\hline stock material quality & 6 & 7 & 3 & 8 & 0 & 0 & 0 & 0 & 0 & 0 & 155 \\
\hline machinist experience & 8 & 3 & 7 & 0 & 0 & 0 & 0 & 0 & 0 & 0 & 141 \\
\hline time & 3 & 0 & 3 & 0 & 0 & 0 & 0 & 0 & 0 & 0 & 51 \\
\hline air moisture content & 0 & 8 & 0 & 0 & 0 & 0 & 0 & 0 & 0 & 0 & 40 \\
\hline cutting oil quality & 6 & 5 & 5 & 0 & 0 & 0 & 0 & 0 & 0 & 0 & 117 \\
\hline micrometer quality & 5 & 0 & 8 & 0 & 0 & 0 & 0 & 0 & 0 & 0 & 115 \\
\hline \multirow[t]{3}{*}{ post machine heat time } & 0 & 5 & 0 & 10 & 0 & 0 & 0 & 0 & 0 & 0 & 85 \\
\hline & 0 & 0 & 0 & 0 & 0 & 0 & 0 & 0 & 0 & 0 & 0 \\
\hline & 0 & 0 & 0 & 0 & 0 & 0 & 0 & 0 & 0 & 0 & 0 \\
\hline
\end{tabular}

Figure 14. Cause and Effect Matrix

The Pareto Diagram is an analysis tool that is used to sort sets of data from "highest" to "lowest" values. It is a tool that can be used to measure counts of defects. This is very important when deciding where resources should be focused. Excel and Minitab software are capable of generating Pareto diagrams. This tool can be used at the beginning stage of a project to baseline the process as well as throughout the project to monitor progress, or effects of the improvements. 


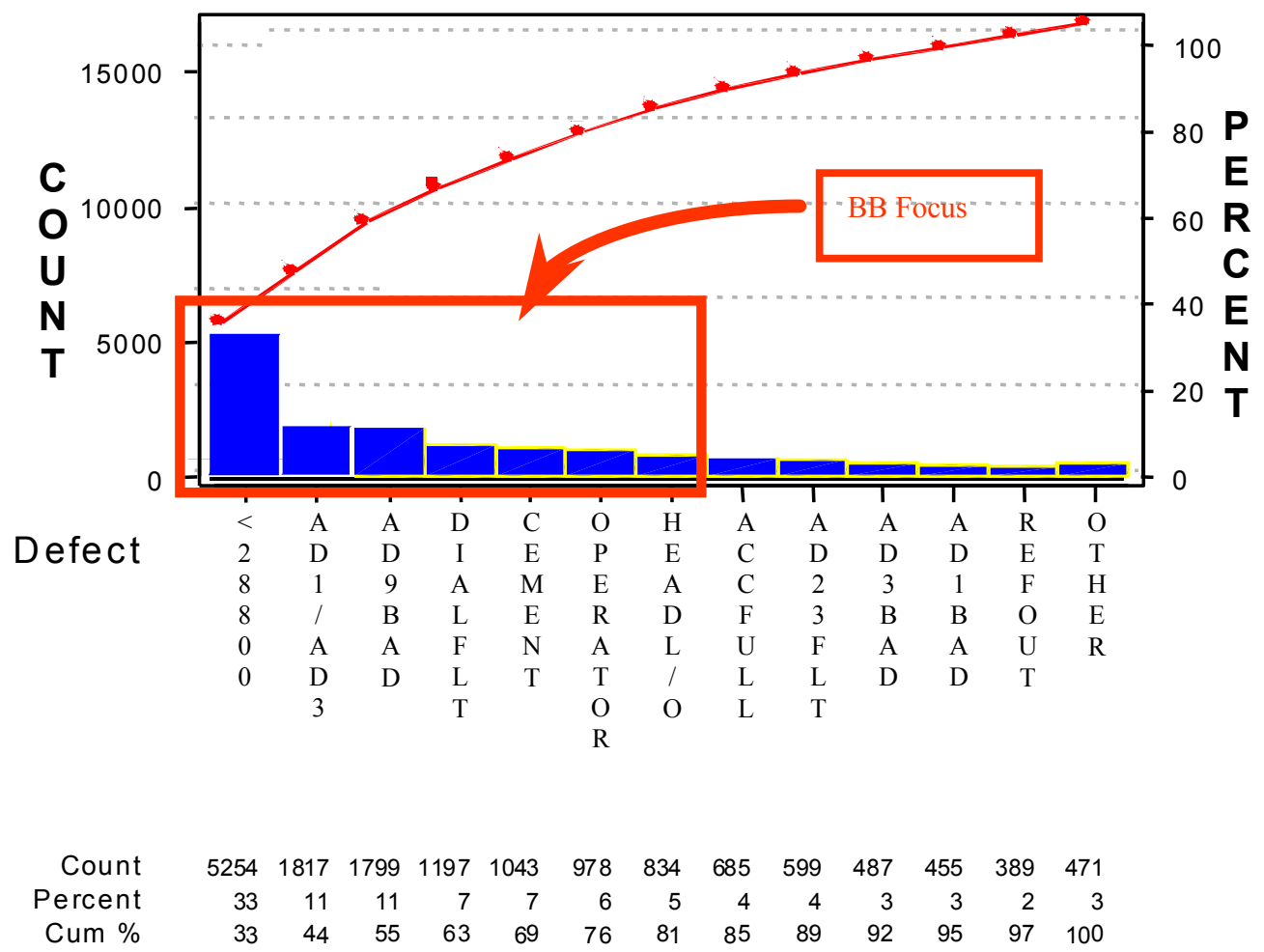

Figure 15. Pareto Diagram from MINITAB

Failure Mode Effects Analysis is a technique used to identify where a process can fail and therefore fosters process improvement. Again, the use of brainstorming with a good technical team is critical. Experienced and knowledgeable team members are also critical in developing FMEAs. The team works through the process map, step-by-step to determine where the process can fail, and then identifies what actions can be taken to prevent those failures. The form in figure 16 is filled out while working through this procedure. FMEA is a very effective tool that can be used for process or design. 


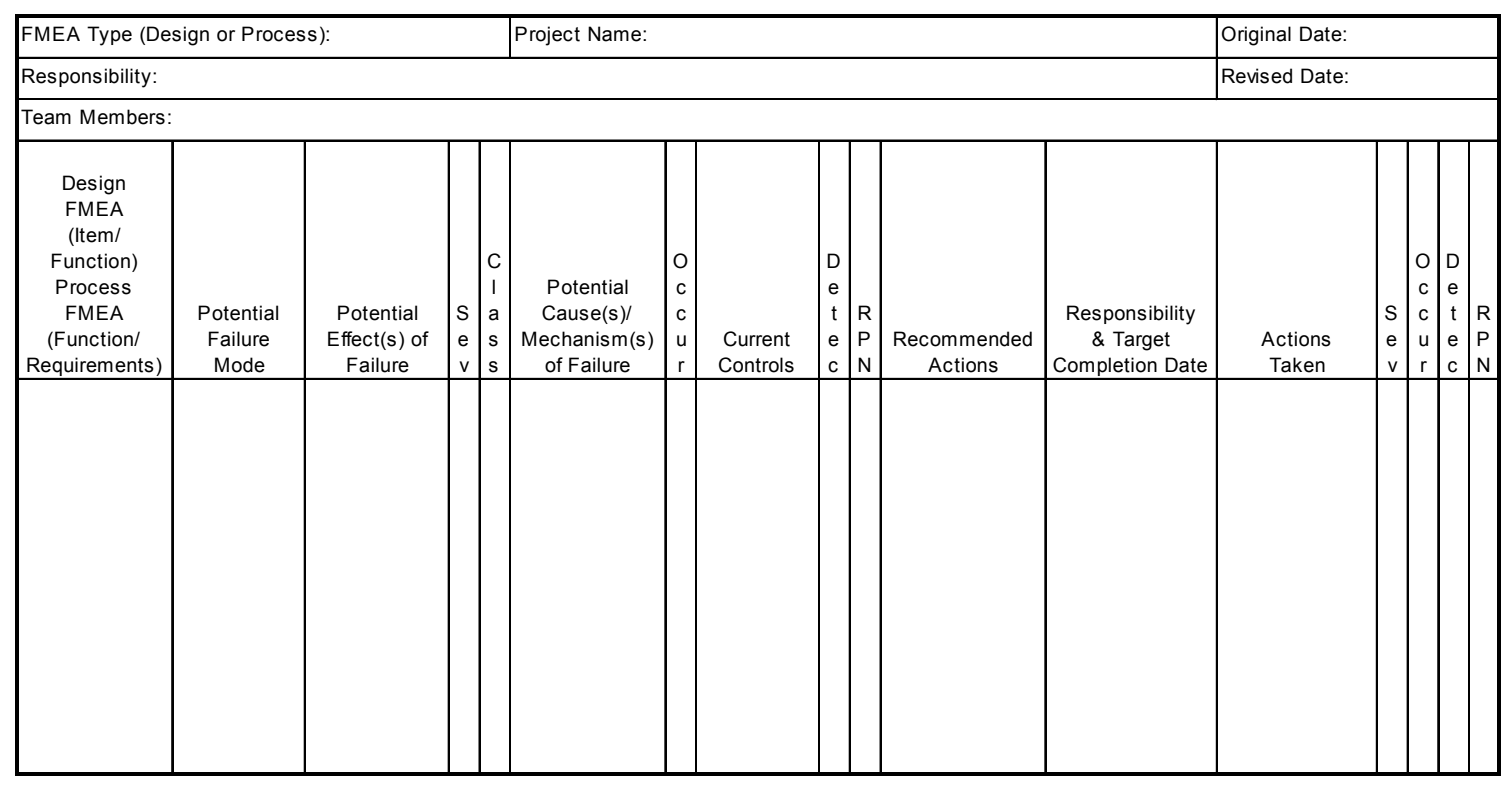

Figure 16. Failure Mode Effects Analysis

Benefits of a properly executed FMEA include [3, p256]:

- Improved product functionality and robustness

- Reduced warranty costs

- Reduced day-to-day manufacturing problems

- Improved safety of products and implementation processes

- Reduced business process problems

Regression Analysis is method of determining the statistical relationship between a response variable (output) and its predictors (inputs) ie. $Y=f(x)$. The objective of a regression analysis is to yield an accurate regression function, which is representative of the process being analyzed. The difference between regression and simple correlation is that regression can be used to develop relationships that help with predicting results. 


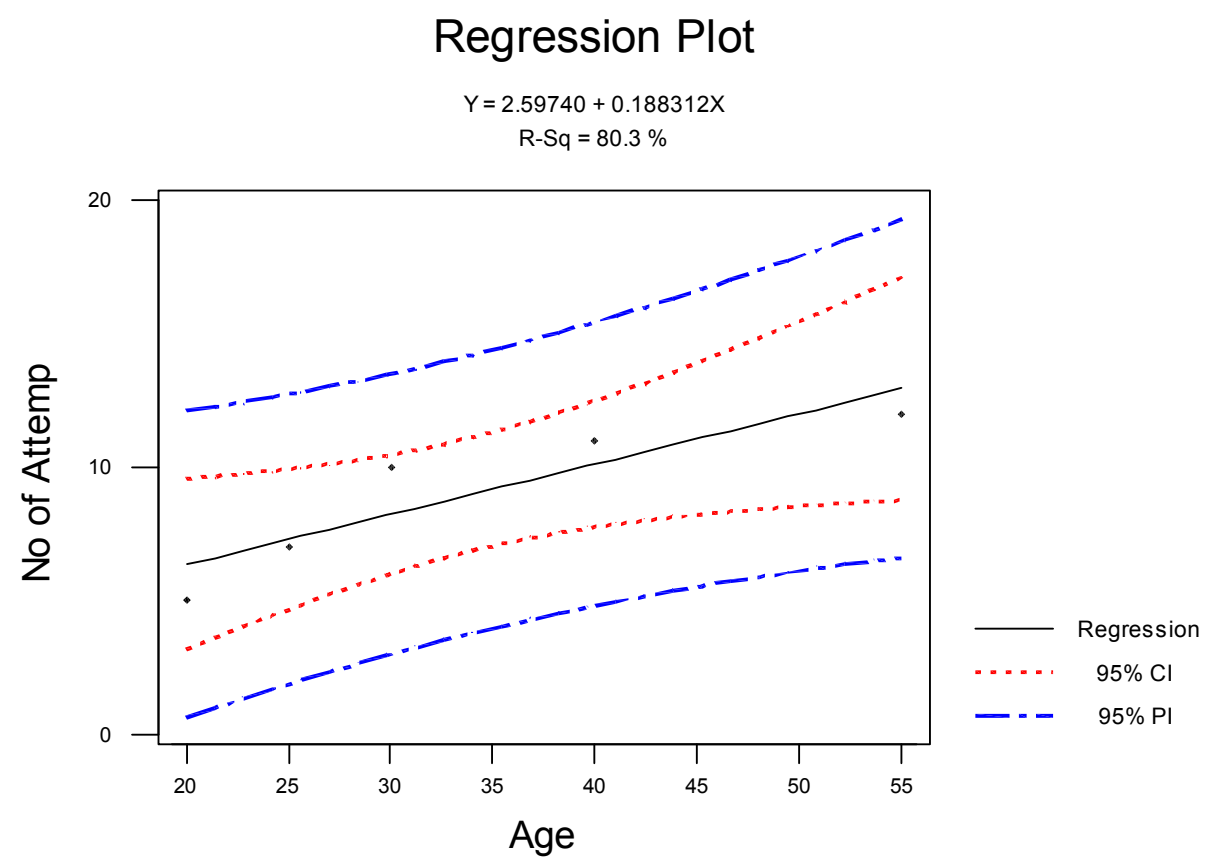

Figure 17. Regression Plot from MINITAB

Models can be Simple (one predictor), Multiple (more than one predictor), Linear and non-Linear. In depth regression analysis is a college course in itself, so for practical purposes, this these will examine only the very basics of Simple Linear Regression. The easiest way to show what regression is all about is graphically. The chart below shows a Simple Linear Regression of number of attempts required by individuals to complete a difficult task ( $\mathrm{Y}$ response variable) to the age of the individual completing the task (X predictor variable) $[9, \mathrm{p} 17]$. The legend to the right shows the regression line (depicted by the formula above $\mathrm{Y}=2.59740+0.188312 \mathrm{X}$ ) and the red dotted line depicts the confidence at which it will fall within on the chart, based on the number of data points. From this model, one could predict how efficient a person may be at these particular tasks, prior to possibly hiring or even interviewing them.

Simulation is "the process of designing a model of a real system and conducting 
experiments with this model for the purpose of understanding the behavior of the system and/or evaluating various strategies for the operation of the system" [8, p3].

There are many software packages used to simulate processes. Simulation is a very powerful tool where the designer builds a model of what is being analyzed. Subprocesses are characterized through input blocks. The blocks are placed in a cumulative model to represent an entire process. The user can then use that model to run variations of the sub-processes to determine the expected outcome. Although not generally used for optimization, it is very helpful for numerous "what if" applications. A well-built model can be used to predict, evaluate, compare, troubleshoot, schedule, and analyze systems. Probably the most useful aspect of a simulation is that it gives you nearly instantaneous results, in comparison to the actual process, with no commitment (except the time spent building the model). There is some risk involved. If a model is not built to truly represent the actual process, it can render false results, which can result in erroneous assumptions, decisions, and ultimately actions by the user. Detailed models of complex processes are not built without much research and work. It is critical that all subprocesses are examined and analyzed to define accurate results prior to modeling. The model is only as accurate as the data that was used to build it. A very powerful tool, simulation is not for the beginner. Simulation modeling takes patience, knowledge, and understanding, both of the process being modeled and of the concept of simulation itself.

\section{$\underline{\text { Improve }}$}

Design of Experiments is a very powerful tool used for process improvement. The basic method of DOE is to observe improvements and degradations of a process as levels of input variables are changed. This will show a level of significance of each 
variable as well as show the interactions between the variables. Analysis of the responses will ultimately result in a prediction model. This tool takes all of the input variables of a given process, or sub-process, and formulates various experiments using different levels of each input variable. Design of Experiments requires an in depth understanding of design philosophy, interaction analysis, and noise effects. However, when used effectively, DOE can render a truly robust system. The DOE looks at all factors (variables) and performs a series of tests at different levels for each factor. Each test will yield results that will be analyzed until the prediction model can be formulated and a truly robust system generated. One disadvantage to DOE is the amount of resources required for some tests. For instance, a simple DOE requiring testing of just 4 factors at 2 levels would require 16 trials $\left(2^{4}\right)$ as shown in Table 5 .

Table 5.

\section{Design of Experiment}

\begin{tabular}{|c|c|c|c|c|}
\hline \multirow{2}{*}{ TRIAL NO } & \multicolumn{5}{|c|}{ FACTOR } \\
\cline { 2 - 5 } & A & B & C & D \\
\hline $\mathbf{1}$ & + & + & + & + \\
\hline $\mathbf{2}$ & + & + & + & - \\
\hline 3 & + & + & - & + \\
\hline $\mathbf{4}$ & + & + & - & - \\
\hline $\mathbf{5}$ & + & - & + & + \\
\hline $\mathbf{6}$ & + & - & + & - \\
\hline $\mathbf{7}$ & + & - & - & + \\
\hline $\mathbf{8}$ & + & - & - & - \\
\hline $\mathbf{9}$ & - & + & + & + \\
\hline 10 & - & + & + & - \\
\hline 11 & - & + & - & + \\
\hline 12 & - & + & - & - \\
\hline 13 & - & - & + & + \\
\hline 14 & - & - & + & - \\
\hline 15 & - & - & - & + \\
\hline 16 & - & - & - & - \\
\hline
\end{tabular}

DOE, like Simulation, is a very powerful tool that can yield outstanding, robust, accurate results. However, it requires dedication, understanding, and commitment. 
Design for Six Sigma is simply a matter of applying the Six Sigma methodology to engineering design application rather than process improvement. The idea is to design equipment to a Six Sigma standard before it goes into manufacturing. Again, to take this literally is sometimes not practical, but the real benefit of this process is that it forces the engineering designers to consider all aspects of getting the part out to the customer through a methodical approach to design. The chart below shows how the normal DMAIC method of the Six Sigma process parallels DFSS.

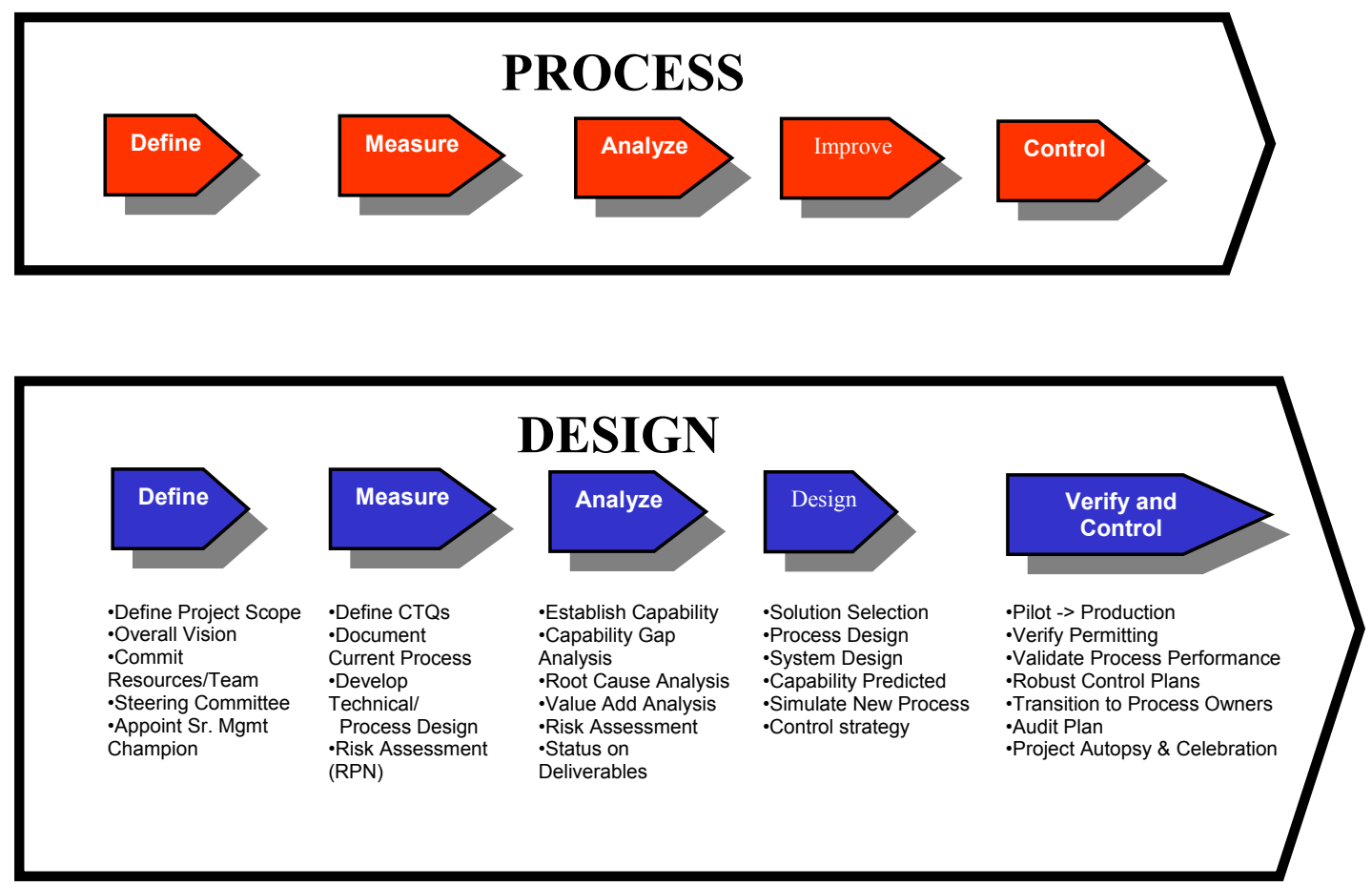

Figure 18. Design For Six Sigma

\section{$\underline{\text { Control }}$}

Manufacturing Process Instructions are used to control processes. They are actual instructions for a procedure on the manufacturing floor. They are used to define exactly how tasks are to be completed for that process. A MPI will identify the purpose 
of the instruction, responsibilities of individuals, equipment required, safety issues, and it will give detailed instructions on how to perform the task. The instruction section should include a process map of the task and step-by-step, detailed instructions of what is to be completed.

Manufacturing Control Plans are used to control processes as the operation is actually running. Manufacturing Control Plans are in chart format and identify step-bystep instructions, in a procedure, of where the control points are. At each control point a measurement, or check, is taken to ensure the process is in control. Control limits will be identified at these points. If the measurement is not within the specified limits, then a corrective action will be identified on the control chart. Manufacturing Control Plans are very useful in maintaining control of a given process and serve as an excellent aid in training new operators. The MCP will generally have one or more control documents associated with it to record the checks and corrective actions taken.

A summary of a control plan can include, in spreadsheet format, the following items: process, process step, input, output, process specification (lower limit, target, and upper limit), Cpk/Ppk (describe sample sizze and methodology to obtain), MSA (include system, $\% \mathrm{R} \& \mathrm{R}$, and $\%$ of tolerance), current control method (include sample size and sample frequency), and reaction plan [3, p555].

Statistical Process Control (SPC) Charts are tools used for measuring the stability of a process and assisting the personnel in reacting to out-of-control conditions. It is becoming common in the manufacturing work place with much more sophisticated means using computer readout in most cases. SPC measures data points of a process as time elapses. Measured against an upper control limit (UCL) and a lower control limit (LCL) the chart will tell you immediately when the process is out of control (after it 
meets certain criteria ie. a certain number of data points outside the control limits, etc.

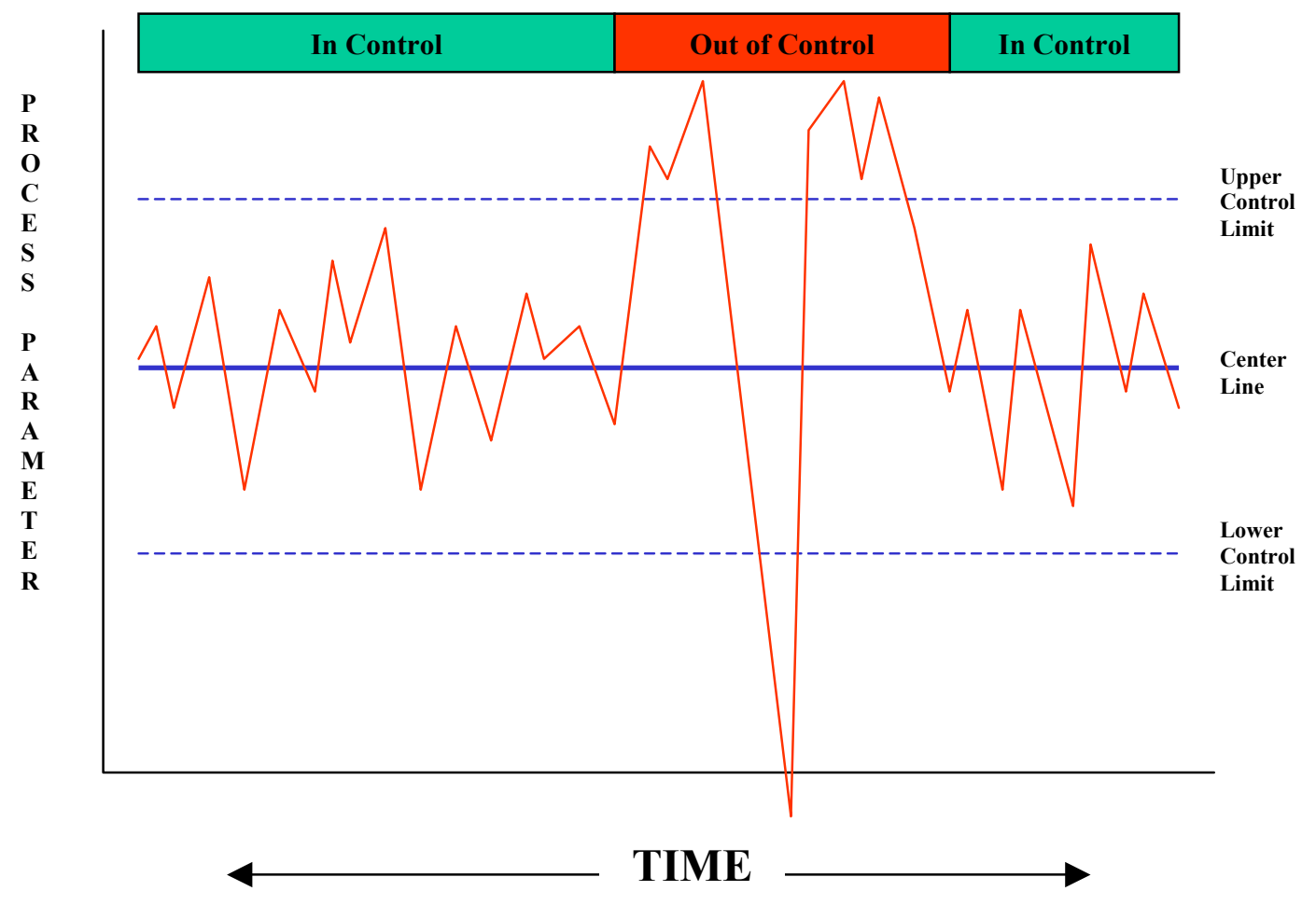

Figure 19. Statistical Process Control Chart 


\section{CHAPTER V}

\section{CASE STUDIES}

\section{Case Study I - Preventative Maintenance}

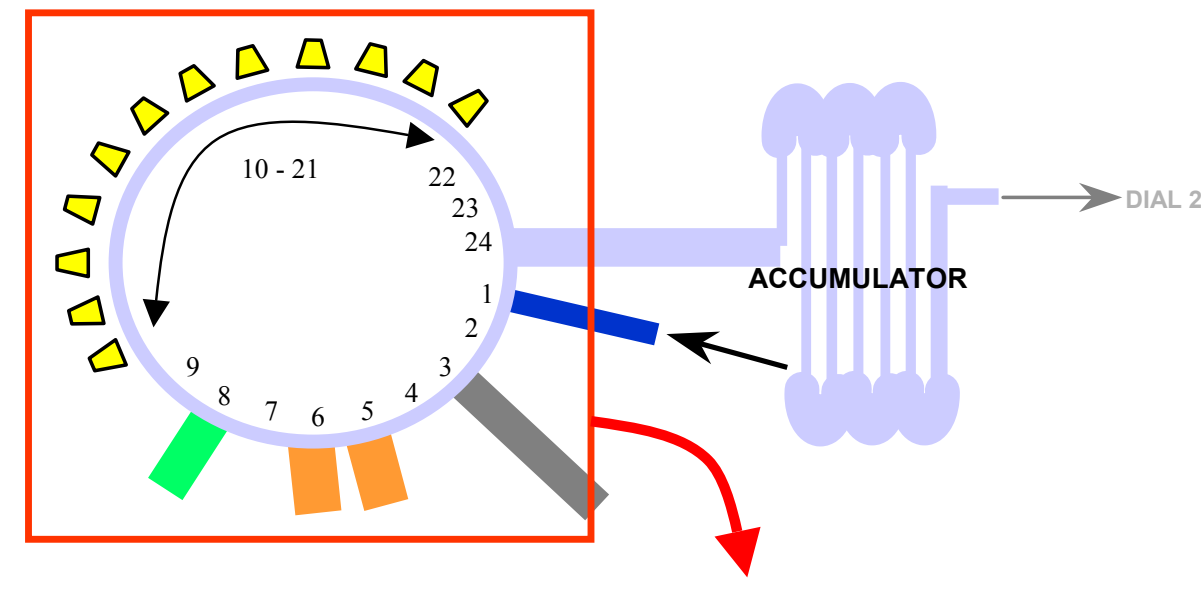

$$
\begin{array}{ll}
1 & \text { Load filament } \\
3 & \text { Load reflector } \\
5 / 6 & \text { Cement filament in reflector } \\
8 & \text { Align filament in reflector } \\
10-21 & \text { Cure cement }
\end{array}
$$

Figure 20. Index Machine Process Map

A lamp assembly machine is operating poorly - only about $75 \%$ efficiency. It is a critical machine in the plant and basically costs the facility $\$ .50$ each time it misses an index. Theoretical index speed is 3 seconds, which means that it is capable of making a finished lamp every 3 seconds. Since the machine indexes every 3 seconds and it costs $\$ .50$ for each missed opportunity, the overall rough estimate for Cost Of Poor Quality 
(COPQ):

[24(hrs/day) x $60(\mathrm{~min} / \mathrm{hr}) \times 60(\mathrm{sec} / \mathrm{min})] / 3(\mathrm{sec} /$ index $)=28800($ theoretical indexes $/$ day $)$ [365(days/yr)-11(holidays)-52(proposed weekend days off) = 302(days of operations/yr) [28800(theor indexes) x 302(days opn/yr) $=8897600$ (theor indexes/yr)

$[8(\mathrm{hrs} / \mathrm{wk}$ PM) $/$ 5(days/wk cap) x 1200(indexes/hr) = 1920(indexes/day PM $)$

302(theo days/yr) x 1920(indexes/day PM) = 579840(indexes/yr PM)

$8897600($ theo indexes/yr) - 579840(indexes/yr PM) $=8317760($ act indexes/yr)

$75 \%$ eff $\rightarrow 8317760($ act indexes $/ y r) \times .25($ defect rate $)=2079440($ missed indexes $/ y r)$

COPQ $\rightarrow$ 2079440(missed indexes/yr) x .50(per index $)=\$ 1039720$ Annual Opportunity

Using a combination of automated data collection and manual data collection, a defect chart was created and analyzed in a rolling 30-day format. Each day a new row of data was collected. The data showed overall production and how many opportunities were missed each day due to respective defect. When data became 31 days old, it was placed in an archive for later analysis of long-term data. At the bottom of the table was recorded the Q1, Q3, stability factor, and mean for each column. After several weeks of analysis, it was obvious that the greatest problem was reacting to downtime caused by maintenance issues. A Pareto Chart was created. It clearly showed that the main issue was downtime due to reactive maintenance. 
Table 6.

Downtime Data

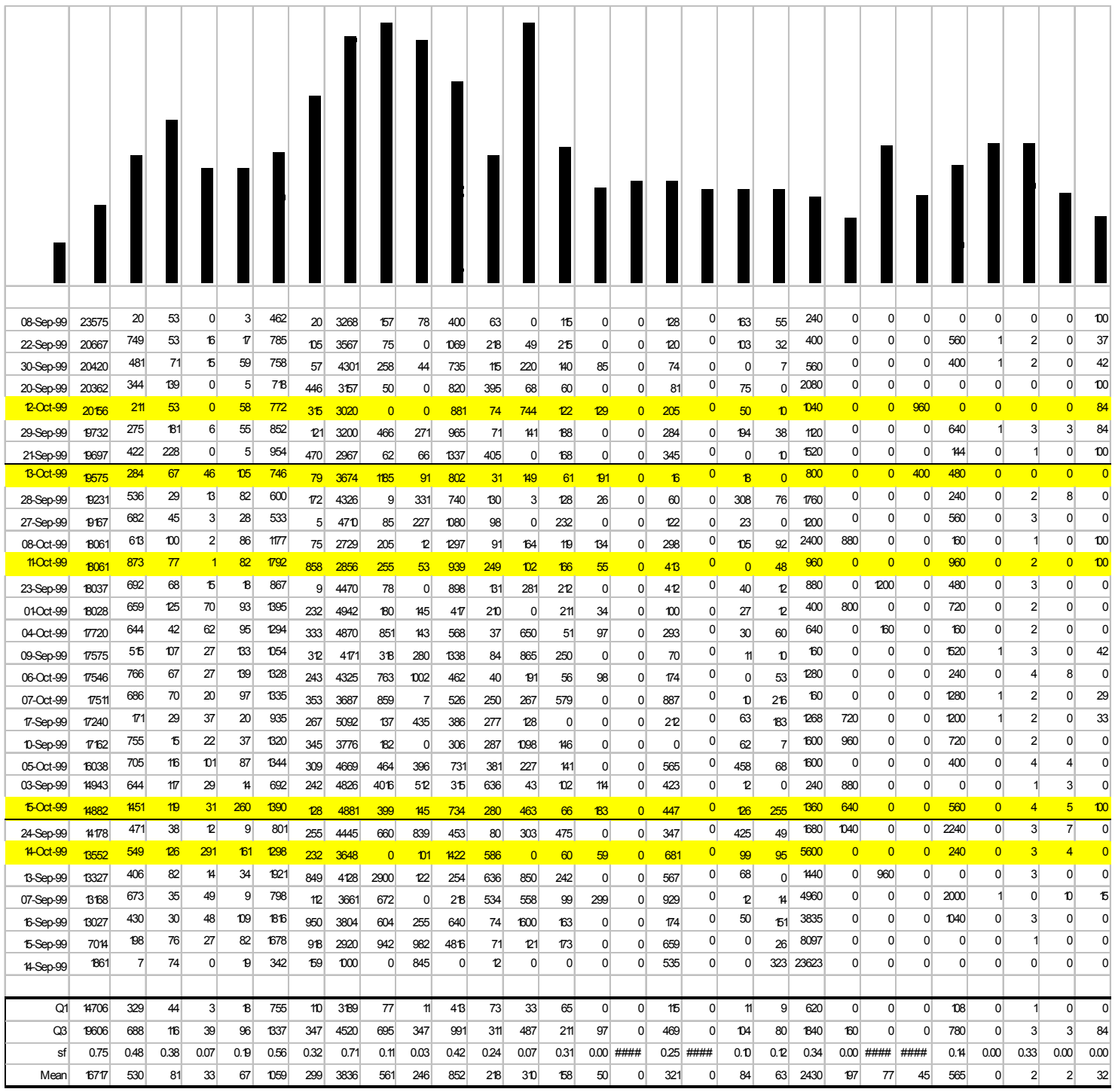

When data became 31 days old, it was placed in an archive for later analysis of long-term data. At the bottom of the table was recorded the Q1, Q3, stability factor, and mean for each column. After several weeks of analysis, it was obvious that the greatest problem was reacting to downtime caused by maintenance issues. A Pareto Chart was created. It clearly showed that the main issue was downtime due to reactive maintenance. 


\section{Pareto Chart for Assembly Machine 2}

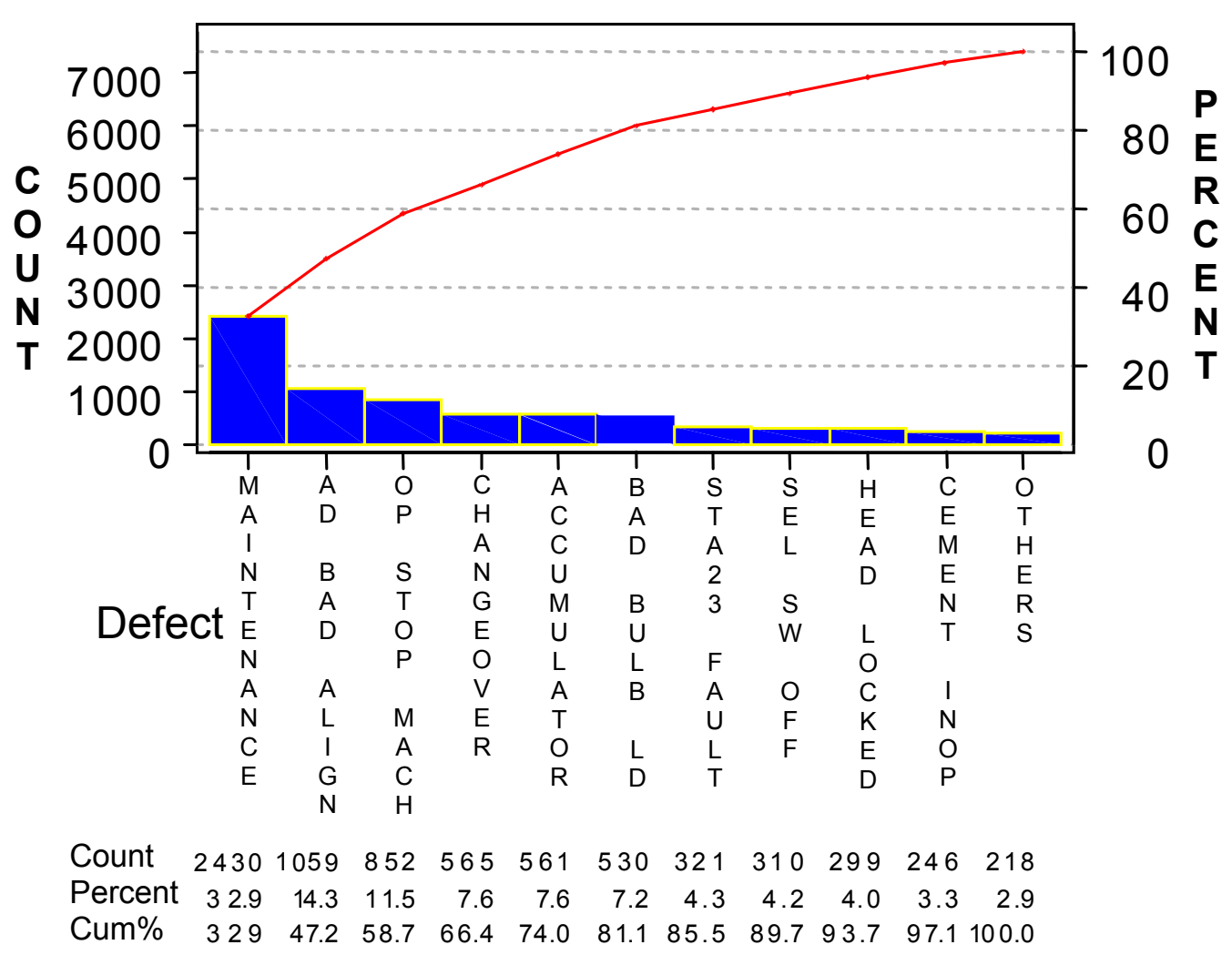

Figure 21. Pareto Chart of Defects

The next step was to examine the variation in the sub-processes. Another consideration from a business standpoint, was to identify any "quick hit" projects. Quick hits are anything that the project manager feels they can resolve immediately or with little effort. By examining the variation in the data collection chart and identifying the primary issues, the Box Plot charts were placed beside each other to examine, graphically, to see if there were other issues that were not obvious from simply looking at the data. The high mean demonstrated the company was losing considerable opportunity from that defect. The high variation suggested that some days were good and some days were bad, so the machine did have the capability of having a good day. If the good days could be modeled and duplicated, then the mean would naturally improve as well. 


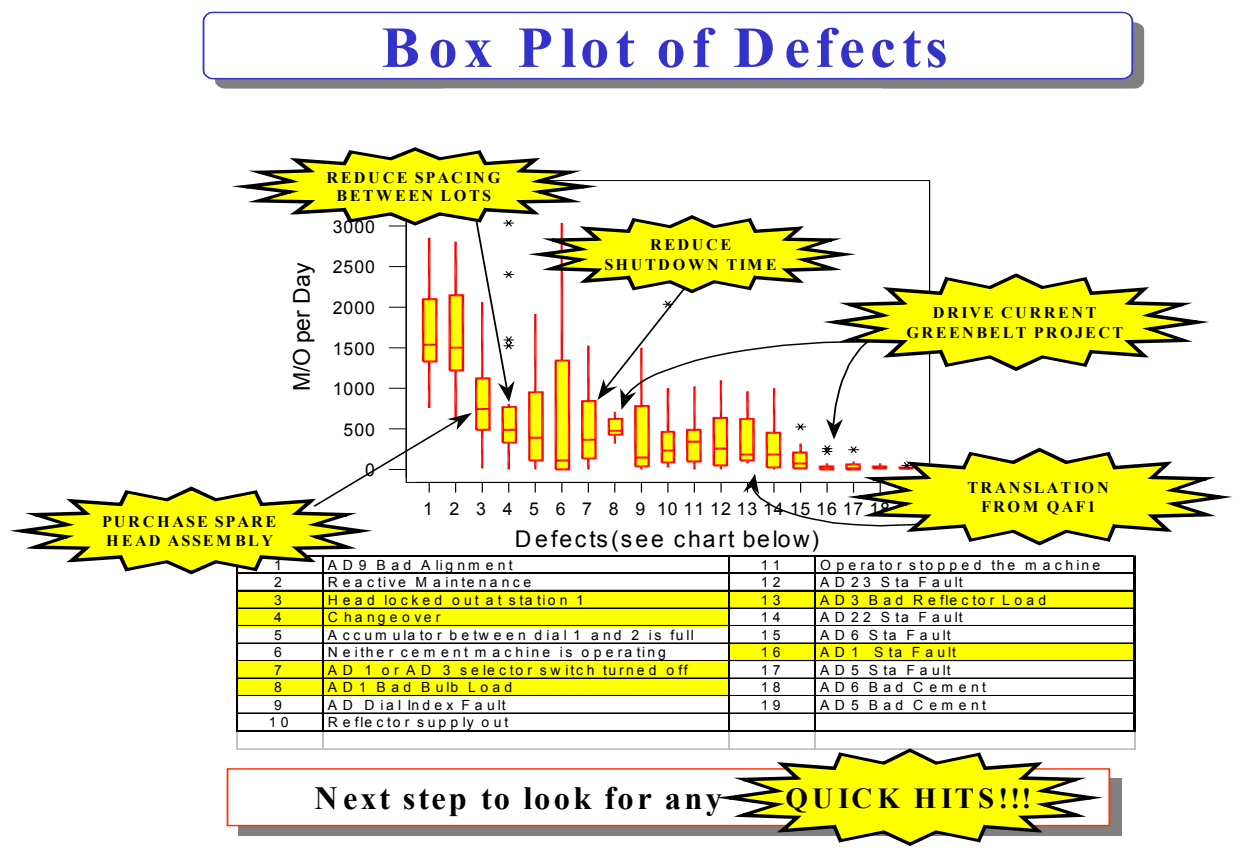

Figure 22. Box Plot of Defects

Quick hits were identified and assigned to Green Belts while more data was collected on the root cause of maintenance downtime. It was interesting to see the amount of difference made in the process simply by analysis after the quick hit projects were introduced. Figure 24 shows a Chi Squared test of the mean, Homogeneity of Variance, and Box Plot which all demonstrate a significant difference simply after a few quick hits. 


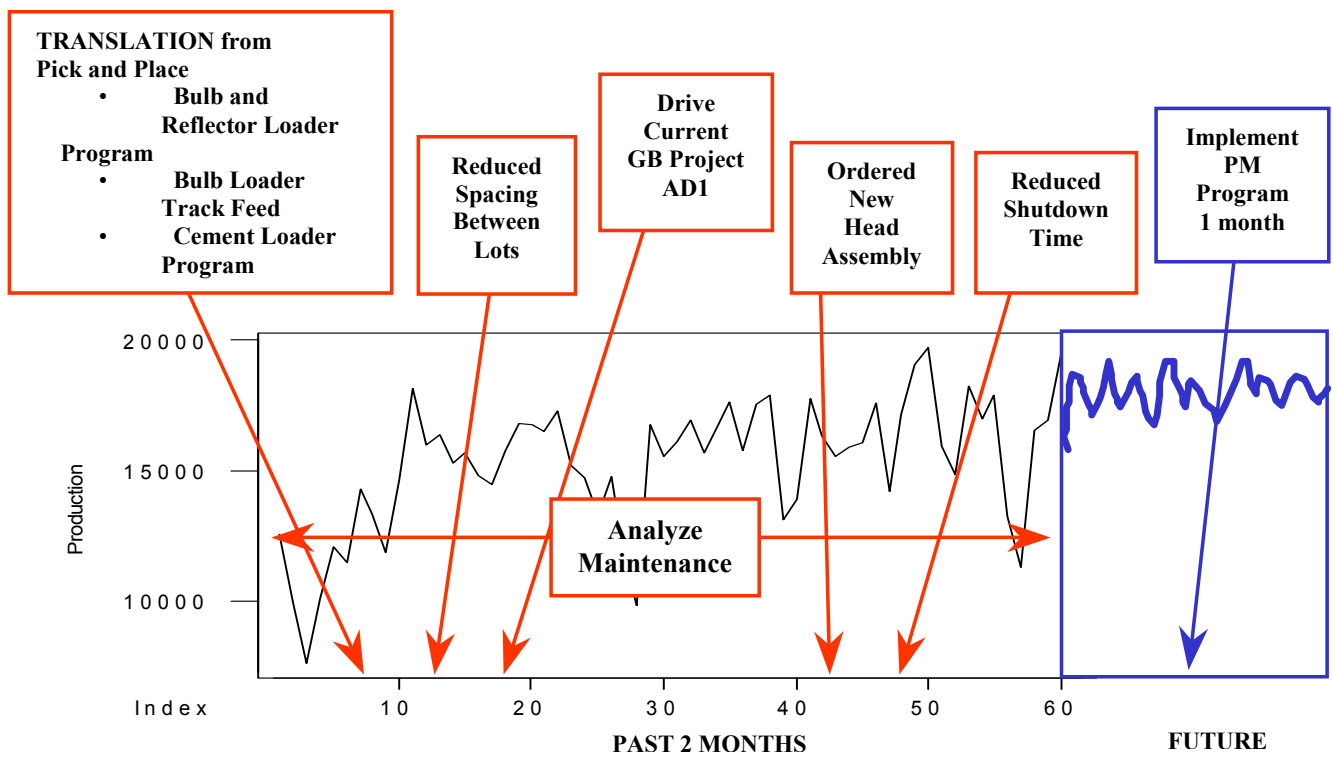

Figure 23. Timeline of Events

The next step was to identify what issues were causing maintenance downtime. A maintenance log was designed that required the operator to record detailed data each time they shut down the machine for any kind of reactive maintenance. The operator would need to log their name, time, duration, what went wrong and how they corrected the problem. Every second of downtime would be accounted for. After several weeks of collecting more data, another cause and effect matrix was generated. Two stations were causing most of the maintenance downtime - reflector loaders and alignment (alignment)station maintenance should not be confused with actually aligning the bulb, which was identified as a separate issue). Each issue was brainstormed on how this downtime would be reduced. The answer was stopping periodically and conducting some maintenance on the stations before they would break down. 


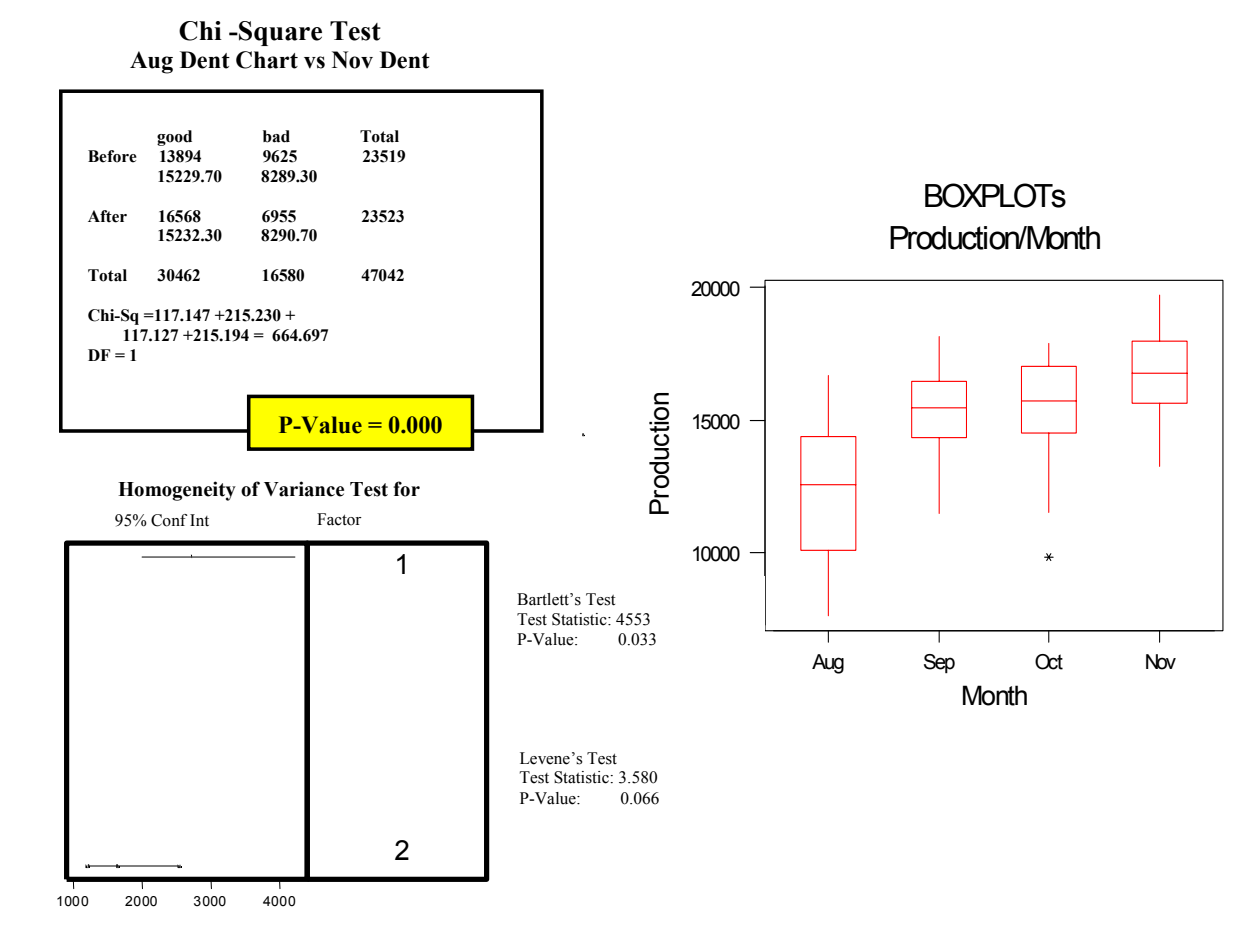

\section{Statistical Improvement in both Variation and Mean}

Figure 24. Significant Difference After Quick Hits

Table 7.

$\underline{\text { Cause and Effect Matrix for Reactive Maintenance }}$

\begin{tabular}{|c|c|c|c|c|}
\hline & & 7 & 5 & \\
\hline & Inputs & 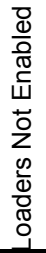 & 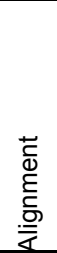 & Total \\
\hline 11 & gripper assembly repair & 90 & 0 & 630 \\
\hline 9 & complete head repair & 84 & 0 & 588 \\
\hline 17 & bad contact & 0 & 100 & 500 \\
\hline 25 & head/nest alignment & 0 & 89 & 445 \\
\hline 10 & contact repair & 60 & 0 & 420 \\
\hline 22 & head opener/closer & 0 & 80 & 400 \\
\hline 3 & gap between lots & 56 & 0 & 392 \\
\hline 12 & neat 203h box assembly & 54 & 0 & 378 \\
\hline 26 & debris under ball slide assembly & 0 & 60 & 300 \\
\hline 19 & low light level (Zenith) & 0 & 50 & 250 \\
\hline 8 & notification & 35 & 0 & 245 \\
\hline 2 & change cups & 31 & 0 & 217 \\
\hline
\end{tabular}

The main result from the brainstorming session and data analysis was that more time 
needed to be spent during the normal planned down time to prevent unplanned down time. Several brainstorming sessions were conducted with all operators to create a Preventative Maintenance control plan. The control plan consisted of a one-line entry into the overall Control Plan for the machine that stated PM would be conducted in accordance with the Maintenance Schedule form. The maintenance schedule was given a form number within the facility document control procedure, and the schedule was implemented. An extract of the maintenance schedule shows that it identifies specific tasks for each shift. These tasks were rotated periodically to ensure each mechanic would stay proficient at the task.

Table 8 .

Maintenance Schedule

\begin{tabular}{|c|c|c|c|c|c|c|c|c|c|c|c|c|c|c|c|c|c|c|}
\hline & & & & & & & & & & & & & & & & & & \\
\hline & & & & & & & 1st Shi & & & 2 nd Sh & & & 3rd Shi & & & & & \\
\hline \multirow[t]{2}{*}{ Job\# } & Station & Item & Action & $\mathrm{Fr}$ & Time & \multicolumn{4}{|c|}{ January } & & \multicolumn{4}{|c|}{ February } & \multicolumn{4}{|c|}{ M arch } \\
\hline & & & & & & $1-3$ & $4-10$ & $11-17$ & $18-24$ & $25-31$ & $1-7$ & $8-14$ & \begin{tabular}{|l|}
$15-21$ \\
\end{tabular} & $22-28$ & $1-7$ & $8-14$ & $15-21$ & $22-28$ \\
\hline 1 & Stock Rm & Parts for next months PM & Order & $\mathrm{M}$ & 30 & & & & & & & & & & & & & \\
\hline 2 & 001 & clutch brake (pick-n-place) & replace & A & 120 & & & & & & & & & & & & & \\
\hline 3 & 001 & cam follower & inspect & $\bar{M}$ & 5 & & & & & & & & & & & & & \\
\hline 4 & 001 & cam follower & replace & $Q$ & 45 & & & & & & & & & & & & & \\
\hline 5 & 001 & sensor & inspect & $\mathrm{M}$ & 5 & & & & & & & & & & & & & \\
\hline 6 & 001 & hopper & clean out & $\mathrm{M}$ & 30 & & & & & & & & & & & & & \\
\hline 7 & 001 & gripper sensor & inspect & $\mathrm{S}$ & 5 & & & & & & & & & & & & & \\
\hline 8 & 001 & pick and place pads & replace & $\mathrm{s}$ & 20 & & & & & & & & & & & & & \\
\hline 9 & 003 & clutch brake (pick-n-place) & replace & $\mathrm{A}$ & 120 & & & & & & & & & & & & & \\
\hline 10 & 003 & brushes & inspect and blow out & $\bar{M}$ & 20 & & & & & & & & & & & & & \\
\hline 11 & 003 & p \& p pads & replace & $\mathrm{s}$ & 30 & & & & & & & & & & & & & \\
\hline 12 & 003 & conveyor & grease & $\mathrm{M}$ & 15 & & & & & & & & & & & & & \\
\hline 13 & 003 & orienter & inspect & W & 5 & & & & & & & & & & & & & \\
\hline 14 & 003 & orienter & replace & $\mathrm{M}$ & 30 & & & & & & & & & & & & & \\
\hline 15 & 003 & clutch brake (accumulator) & replace & $\mathrm{A}$ & & & & & & & & & & & & & & \\
\hline 16 & 005 & chiller antifreeze & inspect & $\mathrm{M}$ & 5 & & & & & & & & & & & & & \\
\hline 17 & 005 & \begin{tabular}{|c|} 
chiller antifreeze \\
\end{tabular} & replace & $\mathrm{A}$ & 60 & & & & & & & & & & & & & \\
\hline 18 & 005 & vibrator & rebuild & A & 15 & & & & & & & & & & & & & \\
\hline 19 & 005 & end assembly, vibrator & replace & $Q$ & 60 & & & & & & & & & & & & & \\
\hline 20 & 005 & bushings, (plw blk), vibrator & replace & $Q$ & 60 & & & & & & & & & & & & & \\
\hline 21 & 005 & \begin{tabular}{|l|} 
brushes ( 12 on machine) \\
\end{tabular} & replace & $2 \mathrm{wks}$ & 30 & & & & & & & & & & & & & \\
\hline 22 & 005 & tubes & replace & $\mathrm{W}$ & 30 & & & & & & & & & & & & & \\
\hline 23 & 006 & chiller antifreeze & inspect & $\mathrm{M}$ & 5 & & & & & & & & & & & & & \\
\hline 24 & 006 & chiller antifreeze & replace & $\mathrm{A}$ & 60 & & & & & & & & & & & & & \\
\hline 25 & 006 & vibrator & rebuild & A & 15 & & & & & & & & & & & & & \\
\hline 26 & 006 & end assembly, vibrator & replace & $Q$ & 60 & & & & & & & & & & & & & \\
\hline 27 & 006 & bushings, (plw blk), vibrator & replace & $\mathrm{Q}$ & 60 & & & & & & & & & & & & & \\
\hline 28 & 006 & \begin{tabular}{|l|} 
brushes ( 12 on machine) \\
\end{tabular} & replace & $2 \mathrm{wks}$ & 30 & & & & & & & & & & & & & \\
\hline 29 & 006 & tubes & replace & W & 30 & & & & & & & & & & & & & \\
\hline 30 & 009 & glass plate & replace & $\mathrm{s}$ & 30 & & & & & & & & & & & & & \\
\hline
\end{tabular}




\section{Case Study II - Reflector Haze}

Clear glass reflectors must be coated with a reflective material in order to be effective in creating the proper lumens and beam of a lamp. It is critical to quality that the

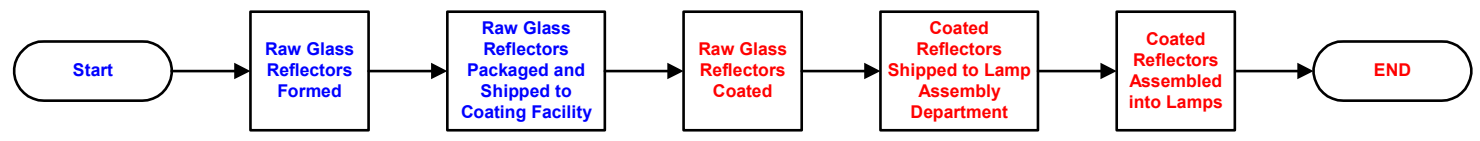

Figure 25. Macro Process Map - Reflector Process

reflector coating meet specific criteria. The coating department ran excessive defects due to haze. Several projects had attempted to resolve issue, but none had been successful. Batches of reflectors for certain runs were resulting in a haze in the reflector coating.

Table 9.

\section{Baseline Cost of Poor Quality}

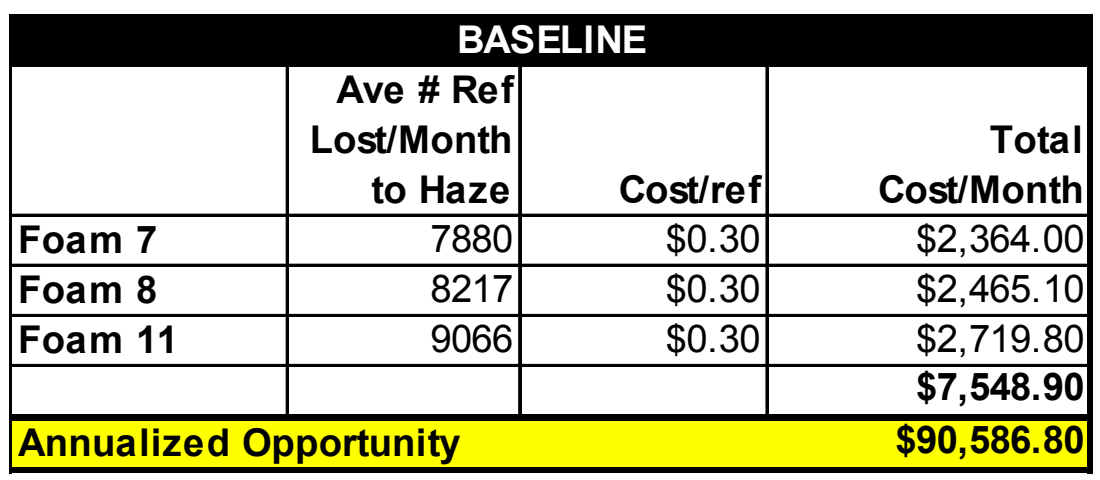

Coating machines are known as FOAMs. The first step was to define the scope of the problem. A team was formed to begin brainstorming what types of haze were being created and what were potential causes of the haze. Three FOAMs were dedicated to reflector coating. All 3 coaters were having issues with haze, but it would not happen on every batch. The causes of haze were identified and a Cause and Effect Matrix 
generated. There were several different types of haze, however, the defects being generated in these cases fell into two categories - Light Haze and Other Haze. Because Light Haze was causing less than $1 / 10$ of the overall defects, it was given a CTQ value of 1 and Other Haze was given a CTQ value of 10.

Table 10.

\section{Cause and Effect Matrix of Haze Defects}

\begin{tabular}{|c|c|c|c|}
\hline & 1 & 10 & \\
\hline Inputs & 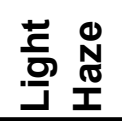 & 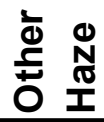 & Total \\
\hline \begin{tabular}{|l|} 
defective reflector molds \\
\end{tabular} & 3 & 4 & 43 \\
\hline dirty molding machines & 8 & 8 & 88 \\
\hline poor raw reflector cleaning & 8 & 8 & 88 \\
\hline poor coating mixture & 2 & 2 & 22 \\
\hline dirty packaging of raw reflectors & 7 & 8 & 87 \\
\hline exposure to debris in warehouse & 7 & 8 & 87 \\
\hline hand residue/oil & 7 & 8 & 87 \\
\hline too much time in coater & 2 & 2 & 22 \\
\hline
\end{tabular}

From the Cause and Effect Matrix, it was apparent that the root cause could have been happening at the facility where the raw reflectors were being molded into shape or at the facility where the raw reflectors were being coated. The molding facility was notified with all of the details and they claimed they were not the cause of the problem because all of their controls to ensure cleanliness were in place. Packaging that arrived at the coating facility was not very clean, neither was the warehouse in which the reflectors were stored. The operators used white cotton gloves whenever handling the raw reflectors and 


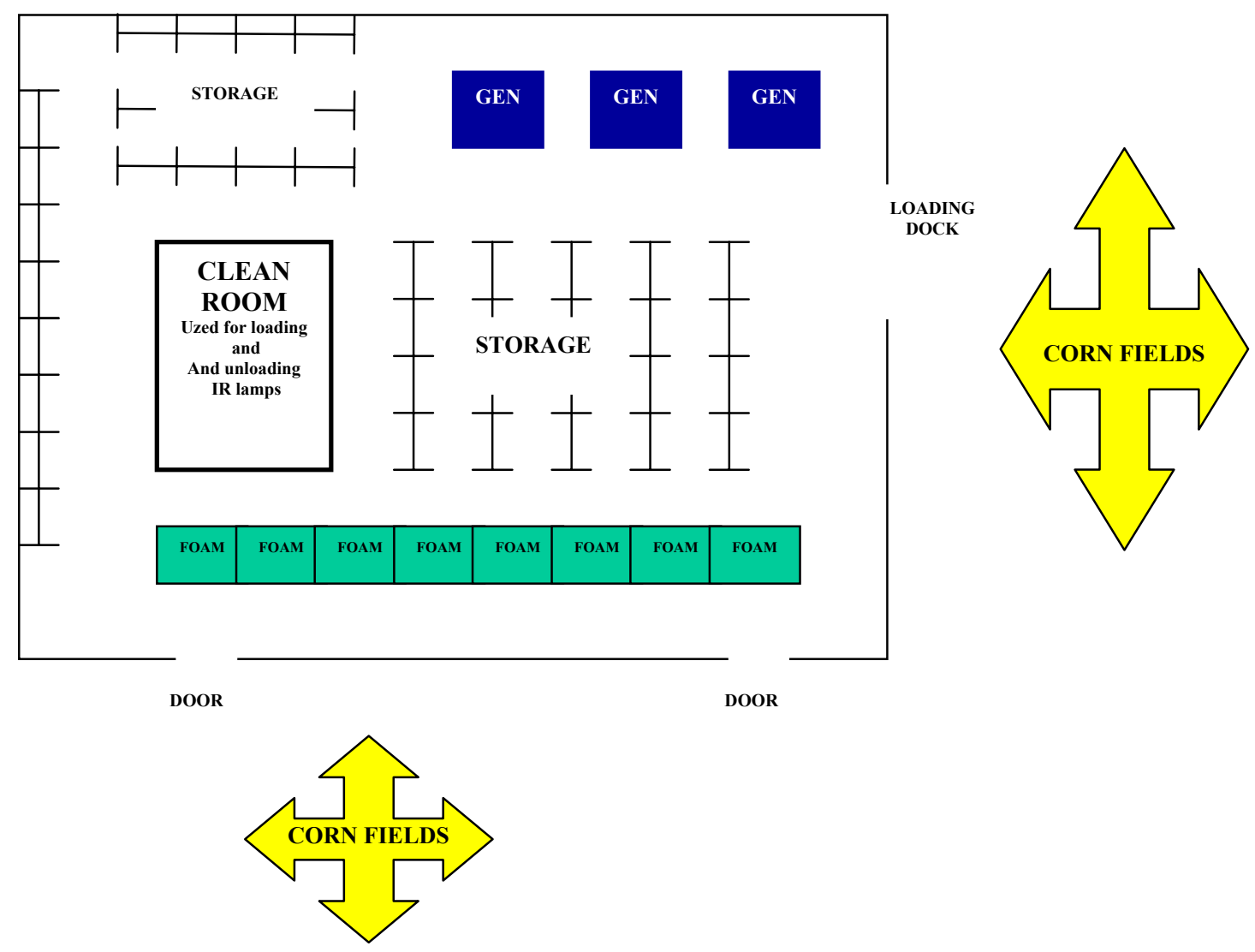

Figure 26. Warehouse Layout

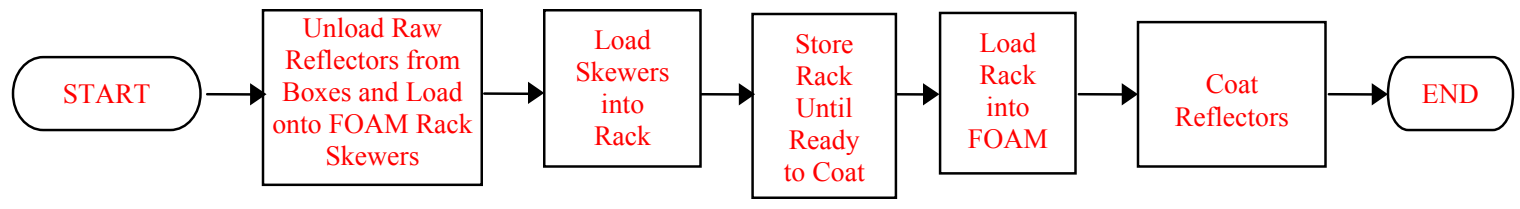

Figure 27. Process Map - Reflector Coating

changed them out for new gloves regularly. Since the team could have more direct impact over the inputs of the warehouse, the team decided to focus on the warehouse first. If that did not turn out to be the root cause, then they would look at the packaging. 
The team turned to what was causing the warehouse to be so dirty. Warehouses are generally not very clean. This warehouse was exceptionally dirty, however, mainly because a cornfield surrounded the facility. When the corn was growing and being harvested, they would get residue from the corn stalks blowing in from the wind. After the corn was harvested, the wind would blow dust from the soil in through the doors. They could not keep the doors shut because is was the shipping and receiving area. Looking back at the process map, the question was raised as to why they needed to load and unload in the warehouse. There was a clean room environment in the middle of the warehouse for other operations. Perhaps there was enough room in the clean room to conduct this operation. A facility layout and redesign was conducted and it was determined that is would be feasible, however, it would take much work. It would be necessary to conduct an experiment to ensure that this would resolve the problem prior to improvement. The team needed to construct a DOE to determine if the warehouse cleanliness was the real issue. Due to the potential expense of testing (creating defects essentially), the experiment needed to remain limited. There were several conditions that affect debris in the warehouse such as temperature, amount of work going on, whether the doors are opened or closed, time of the year in regards to harvesting the corn, etc. However, there was little control over any of these factors. A 2 factor, 2 level design was all that was needed. The two factors would be loading the reflectors into the coating racks and storing the reflectors until coated. The levels would be in the warehouse (dirty) and in the clean room (clean). Since $\mathrm{n}=2^{\mathrm{k}}$, and $\mathrm{k}=2$ this experiment would require 4 runs (or 4 separate experiments). 


\begin{tabular}{|r|c|c|}
\hline \multicolumn{2}{|c|}{ Load Rack } & Store Rack \\
\hline 1 & + & + \\
\hline 2 & + & - \\
\hline 3 & - & + \\
\hline 4 & - & - \\
\hline \multicolumn{2}{|c|}{ Clean (+) } & Dirty (-) \\
\hline
\end{tabular}

Figure 28. DOE for Reflector Coating

Because it had been proven that there was variation in the quality of raw reflectors from the reflector mold facility, this noise had to be eliminated. The 4 experiments would require a total of 54,000 raw reflectors, or about 3.5 pallets. Four pallets were immediately pulled aside. Four empty pallets were placed beside them, and 4 new pallets of reflectors were build by randomly mixing even amounts of reflector cases from each of the original pallets. This would eliminate the noise, because no matter what the defect rate, it would then be relative across each pallet. Again, the purpose of this experiment was not to show that the experiment using the clean room came out much lower than the baseline, but to prove that under the same conditions there was a significant difference between the warehouse and the clean room and that it did have an effect on the haze. And yet another noise factor was the amount of time it took to load and the amount of time it was stored prior to coating. It was determined that these noise factors would have to be controlled during the experiment, even if it meant slowing down production to expose a rack of raw reflectors longer than normal. So the experiments were conducted 


\section{NOISE REDUCTION}

Original Pallets of Raw Reflectors each pallet has variation in defect rate

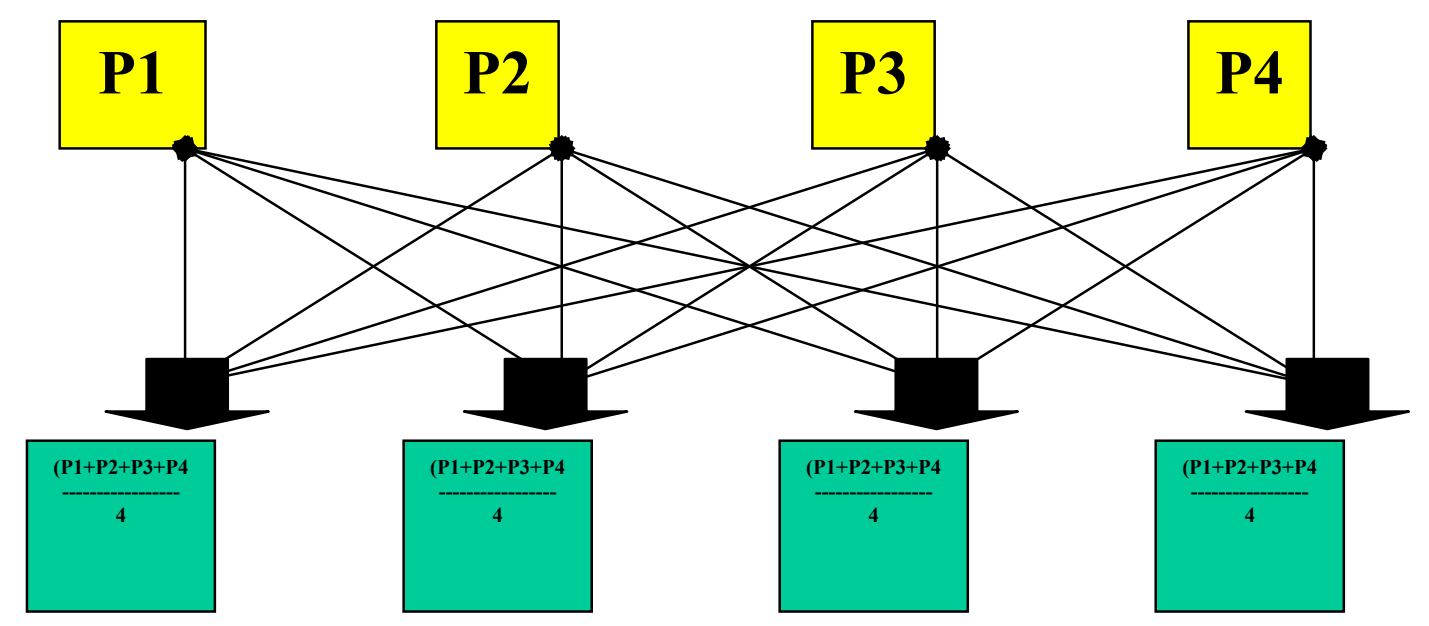

New Pallets Built for Experiment

to reduce noise from variation in in raw reflectors - each pallet now

has equal variation of

$(\mathbf{P 1}+\mathbf{P} 2+\mathbf{P 3}+\mathrm{P} 4) / 4$

Figure 29. DOE Raw Reflector Variation Reduction

all within a few days during a time that the temperature and weather were the same, to eliminate any of these possible noise factors. Figure 30 shows the results of this experiment.

\begin{tabular}{|c|c|c|c|}
\hline & Load Rack & Store Rack & $\%$ Yield \\
\hline 1 & Clean & Clean & 98 \\
\hline 2 & Clean & Dirty & 93 \\
\hline$\overline{3}$ & Dirty & Clean & 95 \\
\hline 4 & Dirty & Dirty & 61) \\
\hline & Clean (+) & Dirty (-) & \\
\hline
\end{tabular}

Figure 30. Reflector Coating DOE Results 
Based on these results, the clean room was reconstructed to make room for loading and storing of raw reflector racks prior to coating. The following 8 months savings resulted.

Table 11.

$\underline{\text { Reflector Coating Project Results }}$

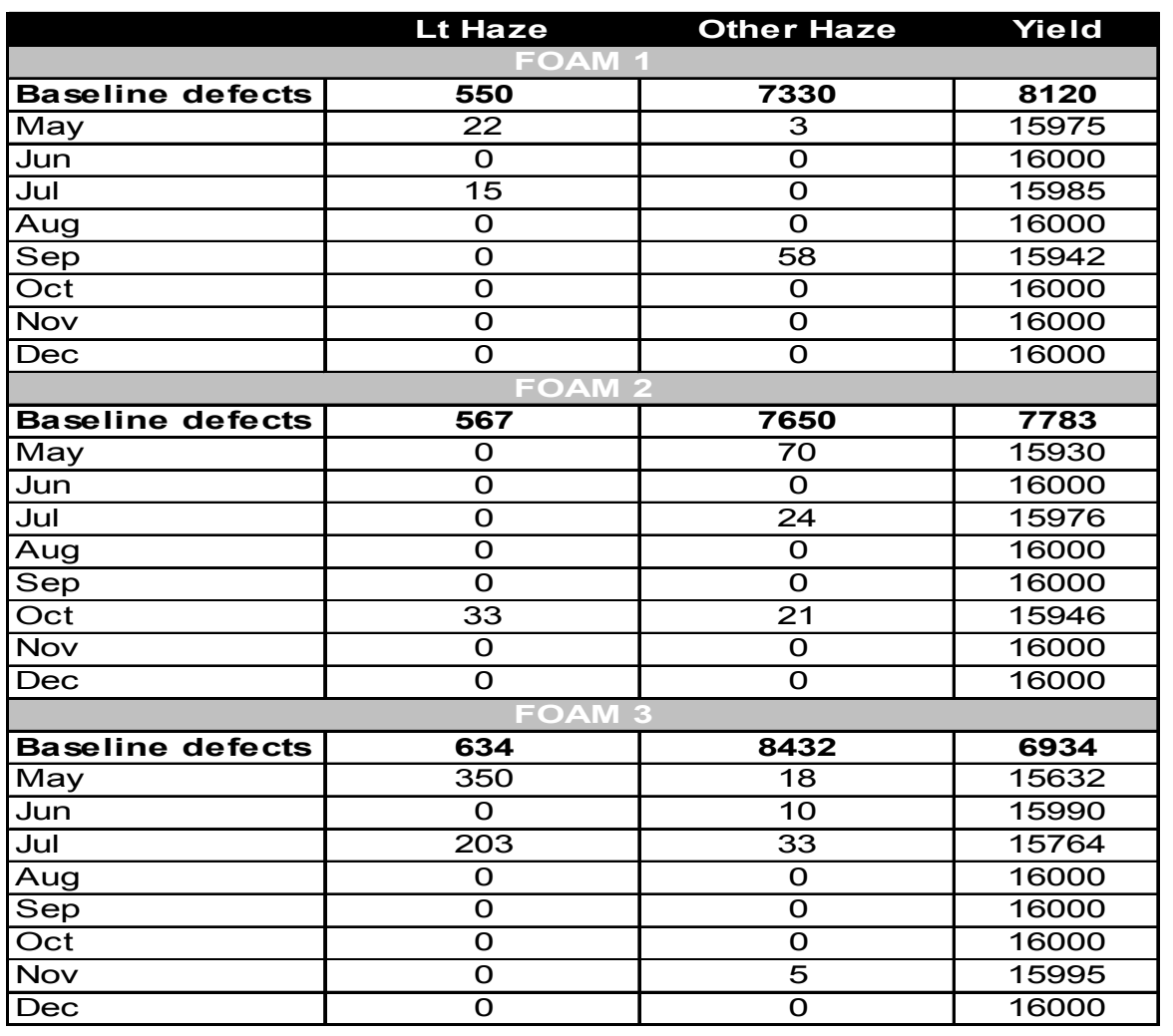

Baseline was established using 4 months of historical data

Table 12.

$\underline{\text { Annualized Savings }}$

\begin{tabular}{|l|c|c|}
\hline \multicolumn{3}{|c|}{$\begin{array}{c}\text { TOTAL SAVINGS } \\
\text { Mef Saved }\end{array}$} \\
\hline Mayth & 24700 & $\$ 7,410$ \\
\hline Jun & 25153 & $\$ 7,546$ \\
\hline Jul & 24888 & $\$ 7,466$ \\
\hline Aug & 25163 & $\$ 7,549$ \\
\hline Sep & 25105 & $\$ 7,532$ \\
\hline Oct & 25109 & $\$ 7,533$ \\
\hline Nov & 25158 & $\$ 7,547$ \\
\hline Dec & 25163 & $\$ 7,549$ \\
\hline Estimated Annualized Savings & $\$ 90,198$ \\
\hline
\end{tabular}




\section{CHAPTER VI \\ SUMMARY, CONCLUSIONS, RECOMMENDATIONS}

During this thesis, an overview was given of the basic principles and methods used in Six Sigma projects. Two areas that were functioning poorly in a lamp manufacturing facility were observed. These areas were analyzed using the same methods taught in General Electric's Six Sigma program.

The processes were improved using a define, measure, analyze, improve, control approach. Teams were gathered to define the initial problems. Data was gathered by various means to analyze. Using data gathering tools, statistical analysis, design of experiments, and process control measures, both processes were improved significantly.

The preventative maintenance project outlined in this document resulted in an annual savings of $\$ 140,000$. The reflector haze project resulted in an annual savings of $\$ 121,000$.

Six Sigma is a program that takes some common industrial and quality engineering tools and applies them as common language across a business. The methods and tools used in Six Sigma projects are nothing new. Industrial engineers and quality engineers have used the methods for decades. Six Sigma is a unique program in that it drives these well-known processes across a business to improve any kind of issue and brings these 
tools as common language for all team members to understand. This fosters teamwork and ultimately results in a better-trained work force who is looking to improve their processes.

One can expect Six Sigma to become more and more popular among businesses - a common language. It is already a part of the curriculum of numerous programs in universities. General Electric is integrating their Six Sigma program into the business more and more every day - not just manufacturing, but all businesses. The principles can be applied to anything, from manufacturing airplanes to improving a golf game. If a business wants to become certified to ISO 9001:2000, they're going to have to adopt a process improvement program. During the last several years General Electric's program has evolved from a very focused, process-oriented program, to a very broad, allencompassing philosophy of daily business. There are two characteristics that have helped General Electric's Six Sigma program to become successful. First, they focused more on Six Sigma as a philosophy rather than a metric. It would be great to get to a Six Sigma level of quality, but not everyone can do that. Metrics are not the most important thing about this program. The most important thing is that it fosters continuous improvement. It gives everyone a common language to understand. The philosophy of Six Sigma is to keep improving. The second input to GE's success is that it was driven from the top down, with total commitment, throughout the business. This is not a program that can be partially implemented. There are always going to be a few engineers and managers in any business that understand some of the common tools used in driving process improvement. The difference with a well-implemented Six Sigma program is that most of an organization's population understands and uses the tools. If implemented 
properly, with total commitment and focus, Six Sigma can render excellent long-term benefits. 


\section{REFERENCES}

(1) Harry, Mikel J., The Vision Of Six Sigma: Tools And Methods For Breakthrough, Sigma Publishing Company, Arizona, 1994.

(2) Harry, Mikel J., The Vision Of Six Sigma: A Roadmap For Breakthrough, Sigma Publishing Company, Arizona, 1994

(3) Breyfogle, Forrest W. III, Implementing Six Sigma: Smarter Solutions Using

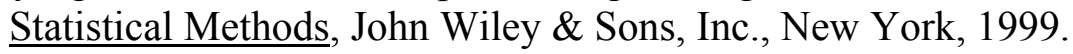

(4) Perez-Wilson, Mario, Six Sigma: Understanding The Concept, Implications, And Challenges, ASC Press, Arizona, 1999.

(5) Pande, Peter S., Neuman, Robert P., Cavanagh, Roland R, The Six Sigma Way: How GE, Motorola, and Other Top Companies Are Honing Their Performance, McGraw- Hill, New York, 2000

(6) Eckes, George, Making Six Sigma Last: Managing The Balance Between Cultural And Technical Change, John Wiley \& Sons, Inc., New York, 2001

(7) Kiemele, Mark J., Schmidt, Stephen R., Berdine, Ronald J., Basic Statistics: Tools For Continuous Improvement, Air Academy Press \& Associates, Colorado, 1997

(8) Pegden, C. Dennis, Shannon, Robert E., Sadowski, Randall P., Introduction to Simulation Using Siman, McGraw -Hill, Inc, 1995

(9) Neter, John, Kutner, Michael H., Nachtsheim, Christopher J., Wasserman, William, Applied Linear Regression Models, Third Edition, Times Mirror Higher Education Group, Inc, 1996

(10) Schmidt, Stephen R., Launsby, Robert G., Understanding Industrial Designed Experiments, Air Academy Press \& Associates, Colorado, 1998

(11) Chase, Nancy, "Six Sigma Blackbelts Stamp Out Tough Quality Problems," Quality, August 1999

(12) Godfrey, A. Blanton, "Six Sigma Quality," Quality Digest, May 1999 
(13) Perez-Wilson, Mario, "Six Sigma Strategies: Creating Excellence in the Workplace," Quality Digest, December 1997

(14) Advanced Systems Consultants,"What is Six Sigma?," September 17, 1999

(15) Maguire, Miles, "Cowboy Quality: Mikel Harry's riding tall in the saddle as Six Sigma makes its Mark," Quality Progress, October 1999

(16) Six Sigma Qualtec, "Pilkington Libby Owens Ford," Momentum, 1998

(17) Six Sigma Qualtec, "GE Capital Mortgage Insurance Canada," Momentum, 1999

(18) Kendall, Jenny and Fulenwider, Donna O., "Six Sigma, E-Commerce Pose New Challenges," Quality Progress, July 2000

(19) Munro, Roderick A., "Linking Six Sigma with QS9000," Quality Progress, May 2000

(20) General Electric Company, Annual Report, 1998

(21) General Electric Company, Annual Report, 1999

(22) General Electric Company, "Six Sigma," May 1999

(23) General Electric Lighting, "What is Six Sigma? Understanding GE Lighting's Quality Initiative," 1996.

(24) Stewart, Thomas A., "America's Most Admired Companies: Why Leadership Matters," Fortune, March 21998

(25) Walmsley, Ann, "Six Sigma," Business Magazine, October 1997

(26) Reinvigorating Six Sigma - Lighting Leads the Way, May 232001

(27) GE Six Sigma Partnering with Customers Workshop Pitch

(28) http://www.sixsigmaqualtec.com

(29) http://www.sixsigmaacademy.com

(30) http://www.ssqc.ge.com (Six Sigma Quality Coach)

(31) MINITAB Release 12.2, Help Section 


\section{CIRRICULUM VITAE}

NAME: $\quad$ Lee E. Leathers

ADDRESS: $\quad$ General Electric

Reuter-Stokes, Inc

8499 Darrow Road

Twinsburg, $\mathrm{OH} 44087$

DOB: $\quad$ December 21, 1966

EDUCATION B.S., Industrial Technology

Eastern Illinois University

1985-1989

TRAINING: General Electric Certified Six Sigma Black Belt

Six Sigma Course

Design for Six Sigma Training

Design of Experiments Training

Personnel Relations Leadership Course

Facilitator Training Course

QS9000 Management Training

Voluntary Protection Program (VPP) Core Team Training

Don Day Ergonomics Course

GE Advanced Manager Course

MILITARY: Engineer Officer Advanced Course (Distinguished Graduate)

Jumpmaster Course (Advanced Parachuting)

Ranger Course

Air Movement Operations Course

Airlift Planners Course

Junior Maintenance Officer Course

Engineer Officer Basic Course

Safety Management Course

Observer/Controller (Training Evaluator) Certification Course

AWARDS \&

RECOGNITION: Lula Craig Collier Scholarship

Dean's Advisory Council

Student Marshal, Applied Sciences Curriculum Committee 
Sigma Pi (Pledge Class President)

Army ROTC Distinguished Military Student (academic award)

ROTC Federal/State Scholarships

\section{PROFESSIONAL}

SOCIETIES: American Society for Quality

Institute of Industrial Engineers

Epsilon Pi Tau (honorary technology fraternity)

Society of Manufacturing Engineers 